VITOR ÁTILA DO PRADO MENDES

ESTUDO SOBRE O PLANEJAMENTO REGIONAL NOS ESTADOS BRASILEIROS

BRASÍLIA, 2016 


\author{
UNIVERSIDADE DE BRASÍLIA \\ FACULDADE DE CIÊNCIAS DA SAÚDE \\ PROGRAMA DE PÓS-GRADUAÇÃO EM SAÚDE COLETIVA
}

VÍTOR ÁTILA DO PRADO MENDES

ESTUDO SOBRE O PLANEJAMENTO REGIONAL NOS ESTADOS

BRASILEIROS

Dissertação apresentada como requisito parcial para obtenção do Título de Mestre em Saúde Coletiva pelo Programa de Pós-Graduação em Saúde Coletiva da Universidade de Brasília.

Orientadora: Profa. Dra. Mariana Sodário Cruz

BRASÍLIA

2016 


\section{ESTUDO SOBRE O PLANEJAMENTO REGIONAL NOS ESTADOS BRASILEIROS}

Dissertação apresentada como requisito parcial para obtenção do Título de Mestre em Saúde Coletiva pelo Programa de Pós-Graduação em Saúde Coletiva da Universidade de Brasília.

Aprovado em:

BANCA EXAMINADORA

Profa. Dra. Mariana Sodário (Presidente)

Universidade de Brasília

Prof. Dr. José Antonio Iturri de la Mata Universidade de Brasília

Prof. Dr. Gustavo Nunes de Oliveira Universidade de Brasília 
Dedico esta obra a Deus, que me capacitou e me guiou durante esta árdua trajetória. À minha esposa, família e amigos que me apoiaram e me deram forças para continuar perseguindo os meus objetivos. 


\section{AGRADECIMENTOS}

É com grande alegria que agradeço primeiramente à Deus por ter me capacitado e me guiado nesta trajetória, me dando saúde, paz e alegria para seguir em frente e concluir este processo.

Em segundo lugar agradeço à minha amada esposa, que acreditou em mim, se dedicou em me apoiar e motivar. A agradeço por ter abandonado tantos momentos de lazer e descanso para me acompanhar nesta trajetória, confiando no meu sucesso.

Agradeço aos amigos e familiares que entenderam a minha ausência em todos os momentos onde o compromisso com os estudos foi maior que qualquer momento de distração.

Agradeço ainda à minha querida orientadora, Mariana Sodário, por toda a dedicação e paciência comigo, confiando na minha capacidade e nas minhas opiniões, me orientando e instruindo em todo este processo.

Por fim, agradeço à Universidade de Brasília pela oportunidade em realizar este estudo alcançando o tão sonhado título de mestre. À Grasiela Damasceno pela compreensão e apoio com as liberações durante os meus compromissos profissionais. Ao CONASEMS e ao Departamento de Articulação Interfederativa da SGEP pelo apoio institucional. 
Não deixe que a saudade sufoque, que a rotina acomode, que o medo impeça de tentar. Desconfie do destino e acredite em você.

Gaste mais horas realizando que sonhando, fazendo que planejando, vivendo que esperando. Porque, embora quem quase morre esteja vivo quem quase vive já morreu.

(Fernando Pessoa) 


\section{RESUMO}

O planejamento regional $(\mathrm{PR})$ em saúde pode ser compreendido como estratégia importante para o fortalecimento do planejamento ascendente no SUS, principalmente a partir da publicação do Decreto 7508 em 2011. A partir dessa premissa, o objetivo do presente estudo foi descrever se o PR foi abordado pelos planos estaduais de saúde dos Estados brasileiros, relativos ao quadriênio de 2012 a 2015, considerando a sua prevalência; existência de estratégias e metas para sua operacionalização e a indicação de atores responsáveis pela sua execução. Tratouse de estudo descritivo, realizado por meio da análise documental de 26 planos estaduais de saúde disponibilizados no período, com exceção do Distrito Federal. Dezesseis Estados citaram o PR em seus planos, entretanto, apenas cinco declararam construí-lo. Doze Estados citaram estratégias para operacionalização do PR, em seu maior número relacionadas ao plano diretor de regionalização, à construção da programação pactuada integrada, do plano diretor de investimentos, do contrato organizativo de ação pública e dos mapas da saúde. Os atores citados para esse processo foram as Secretarias Estaduais de Saúde e o CONASS. O estudo identificou que foram descritas iniciativas voltadas à regionalização, entretanto, ainda são tímidos os avanços obtidos na construção do planejamento regionalizado e integrado em saúde.

PALAVRAS-CHAVE: Planejamento Regional; Gestão em Saúde; Regionalização, Planejamento em Saúde. 


\section{ABSTRACT}

The regional health planning $(\mathrm{RP})$ can be understood as an important strategy for strengthening the ascendant planning at the SUS, especially since the publication of Decree 7508 in 2011 . From this premise, the objective of this study was to describe the RP was covered by state health plans of Brazilian states, for the 2012-2015 quadrennium, considering its prevalence; existence of strategies and goals for its operations and the statement of actors responsible for its implementation. This was a descriptive study, conducted through documental analisis of 26 state health plans available in the period, with the exception of the Federal District. Sixteen states cited the PR in their plans, however, only five declared build it. Twelve states cited strategies to operationalize the $\mathrm{RP}$, in its more related to the director plan of regionalization, the construction of integrated agreed schedule, chief investment plan, the organizational contract of public action and health maps. The actors cited for this process were the State Health Departments and CONASS. The study identified that focused on regionalization initiatives have been described, however, are still timid progress achieved in the construction of regionalized planning and integrated health.

KEYWORDS: Regional Health Planning, Health Management, Health Planning. 


\section{LISTA DE QUADROS E TABELAS}

QUADRO 01 - Síntese da metodologia de construção do plano estadual de saúde dos Estados brasileiros $2011-2015$.

QUADRO 02 - Síntese de resultados de análise.

TABELA 01 - Relação entre Estados brasileiros com sua população e respectivas regiões de saúde.

TABELA 02 - Relação entre o número de regiões de saúde nos Estados e a presença do PR nos planos de saúde.

TABELA 03 - Relação entre a população dos Estados e a presença do PR nos planos de saúde.

TABELA 04 - Quantidade de planos com indicadores da análise de situação apresentados na base municipal, regional ou estadual. 
CIB - Comissão Intergestora Bipartite

CIR - Comissão Intergestora Regional

CIT - Comissão Intergestora Tripartite

CNS - Conselho Nacional de Saúde

CGR - Colegiado Gestor Regional

COAP - Contrato Organizativo de Ação Pública

CONASEMS - Conselho Nacional de Secretarias Municipais de Saúde

CONASS - Conselho Nacional de Secretários de Saúde

COSEMS - Conselho de Secretarias Municipais de Saúde

DRS - Diretorias Regionais de Saúde

IBGE - Instituto Brasileiro de Geografia e Estatística

MS - Ministério da Saúde

NOAS - Norma Operacional de Assistência à Saúde

NOB - Norma Operacional Básica

PDI - Plano Diretor de Investimento

PDR - Plano Diretor de Regionalização

PDRI - Plano Diretor de Regionalização e Investimentos

PES - Planejamento Estratégico Situacional

PGASS - Programação de Assistência em Saúde

PPA - Plano Pluri Anual

PPI - Programação Pactuada e Integrada 
PR - Planejamento Regional

RENAME - Relação Nacional de Medicamentos Essenciais, institui o

RENASES - Relação Nacional de Ações e Serviços Essenciais

RRAS - Redes Regionalizadas de Atenção à Saúde

SES - Secretaria Estadual de Saúde

SUS - Sistema Único de Saúde 


\section{SUMÁRIO}

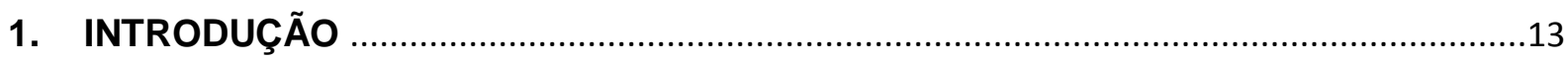

2. OBJETIVOS

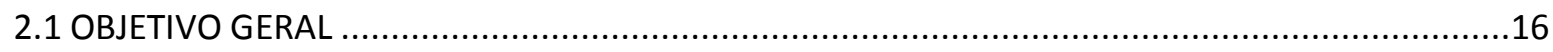

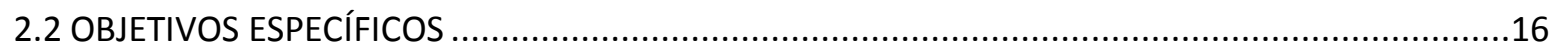

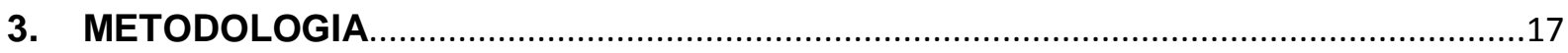

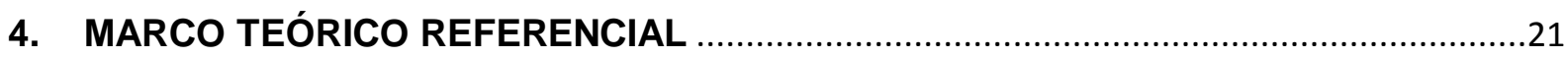

4.1 ASPECTOS HISTÓRICOS DA REGIONALIZAÇÃO EM SAÚDE .......................................................22

4.2 O PROCESSO DE PLANEJAMENTO INTEGRADO E REGIONALIZADO NO SUS .............................27

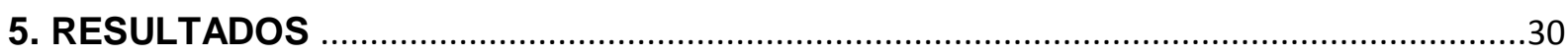

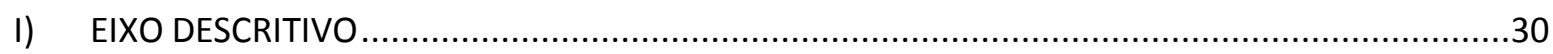

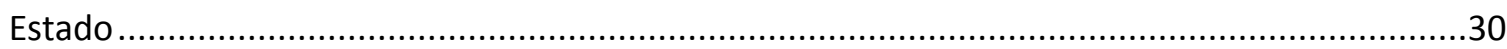

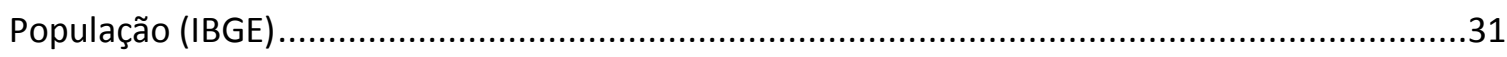

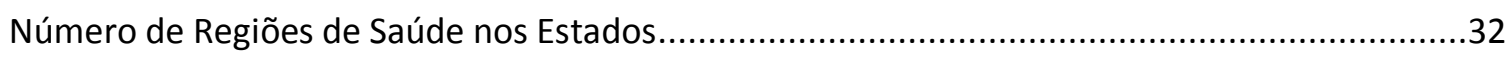

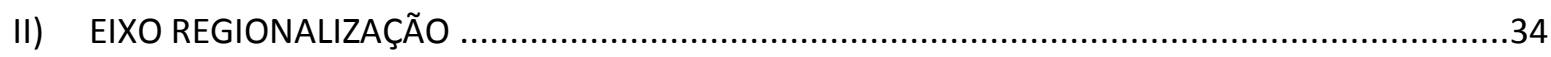

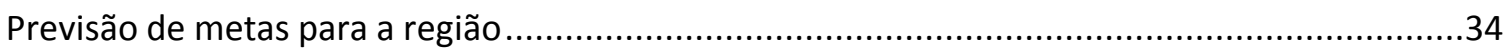

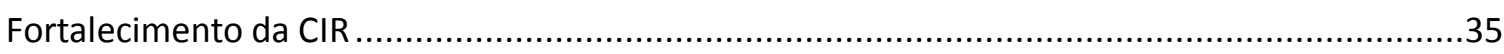

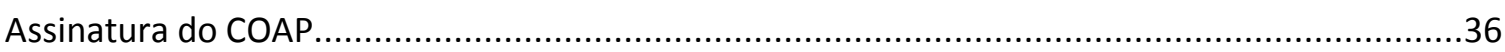

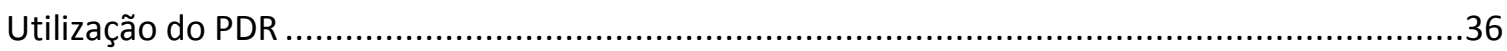

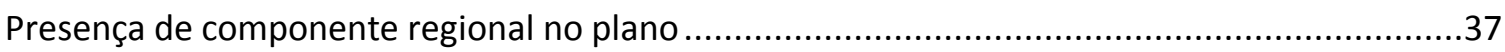

Indicadores da análise de situação em base Municipal, Regional ou Estadual .............................37

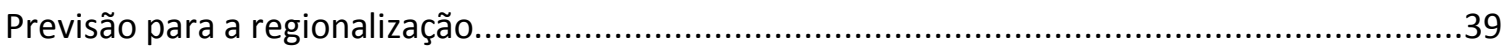

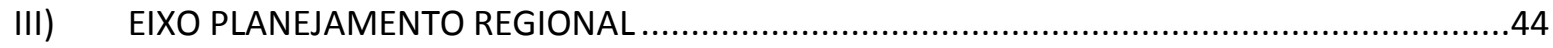

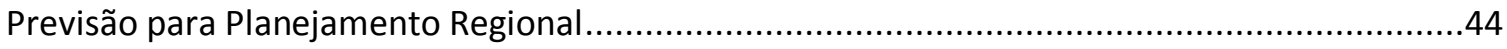

Previsão de ações, metas, diretrizes ou objetivos no âmbito do Planejamento Regional.............45

O que foi previsto no âmbito do planejamento regional ...........................................................

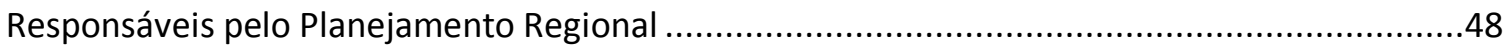

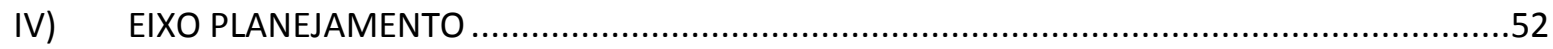

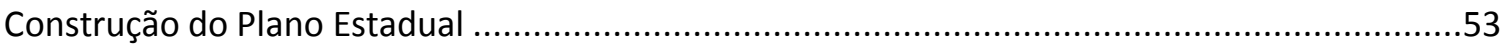

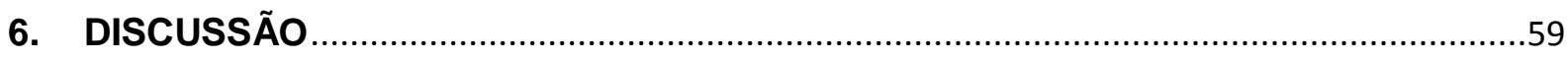

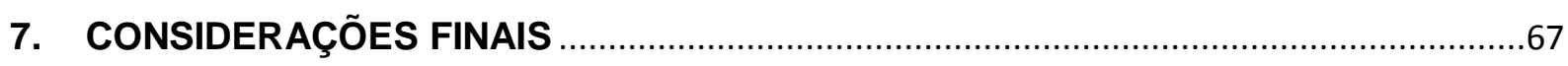




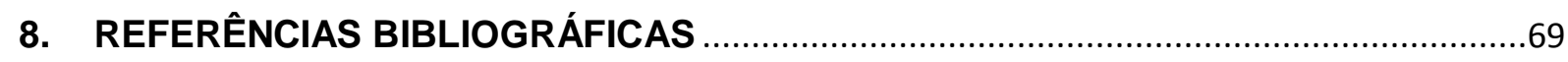

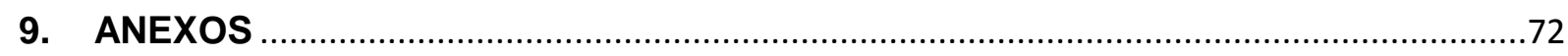

Anexo 01 - MATRIZ PARA ANÁLISE DOS PLANOS ESTADUAIS …........................................72

Anexo 02 - ARTIGO SUBMETIDO À REVISTA PHYSIS …..................................................73

ESTUDO SOBRE O PLANEJAMENTO REGIONAL NOS ESTADOS BRASILEIROS 


\section{INTRODUÇÃO}

A descentralização do Sistema Único de Saúde (SUS), instituído na Constituição Federal de 1988, e definido anteriormente na criação do Sistema Único e Descentralizado de Saúde (SUDS), estimulou uma divisão dos poderes da administração pública na prestação dos serviços de saúde, com ênfase no processo de municipalização. Entretanto, percebeu-se que a descentralização voltada para a municipalização dos serviços poderia proporcionar um conjunto de sistemas de saúde municipais e estaduais fragmentados, isolados e independentes, que não teriam condições de sustentar seus serviços de saúde e atender de maneira integral as necessidades de sua população (BRASIL, 2015a).

Desta forma, a descentralização da política de saúde articulou-se à regionalização quando ficou claro para os gestores a necessidade de articulação politica-administrativa para superação de tal fragmentação. Ou seja, apesar de não ter sido movimento claro na consolidação da universalidade e da integralidade do sistema de saúde, a descentralização só poderia atingir tais objetivos se acompanhada de um processo claro de regionalização do sistema.

Por definição, a regionalização do sistema de saúde trata-se de uma estratégia para a reorganização e orientação da descentralização das ações e serviços de saúde, proporcionando direcionalidade regional para as políticas de saúde, reorientando os processos de negociação e articulação interfederativa entre os gestores do SUS (GIL et al, 2006; BRASIL, 2006).

A regionalização no Sistema Único de Saúde teve avanço importante a partir do ano 2000, principalmente se considerarmos a evolução de seus marcos legais, com destaque para a edição da NOAS em 2002, do Pacto Pela Saúde em 2006 e do Decreto 7.508 em 2011. Dessa forma, durante a década de 1990 pouco se produziu sobre a regionalização no SUS, mas sim, como seriam desenvolvidos os processos de descentralização e municipalização do sistema de saúde.

No entanto, vale ressaltar que a Constituição Federal de 1988 e a Lei Orgânica da Saúde, já previam que a organização e oferta dos serviços de saúde 
deveriam respeitar o princípio da regionalização. O Decreto 7.508 é um importante documento que veio para regulamentar uma parte da Lei 8.080, em especial a que tange a organização do SUS quanto à regionalização, estabelecendo, por exemplo, o Contrato Organizativo de Ação Pública - COAP, o conceito de região de saúde, a realização do planejamento integrado e regionalizado, a construção do Mapa da Saúde, e ainda, organizar a conformação da oferta das ações e serviços de saúde por meio das redes regionalizadas e integradas da saúde (BRASIL, 2011).

De acordo com o Decreto, a região de saúde é definida como:

...o espaço geográfico contínuo constituído por agrupamentos de municípios limítrofes, delimitado a partir de identidades culturais, econômicas e sociais e de rede de comunicação e infraestrutura de transportes compartilhados, com a finalidade de integrar a organização, o planejamento e a execução de ações e serviços de saúde. (art. $2^{\circ}$, I)

Ressalta-se que nesta região o usuário deve encontrar os serviços adequados que sejam capazes de atender as suas necessidades de saúde. Sendo assim, neste espaço definido como região de saúde, devem ser oferecidos, no mínimo, os serviços de: 1) atenção primária; 2) urgência e emergência; 3) atenção psicossocial; 4) atenção ambulatorial especializada e hospitalar; 5) vigilância em saúde. A oferta destes serviços será por meio da rede integrada e regionalizada, que deverá ser pactuada entre os entes federativos que integrarem a região. (BRASIL, 2011)

O Decreto trouxe o planejamento regional ao dispor em seu artigo 6 que a região será referência para a transferência de recursos entre os entes federados. Esse movimento faz com que a região de saúde e suas características, como população e situação sociossanitária, sejam avaliadas para definir a necessidade populacional, não mais a partir de cada ente federado, mas a partir de um território delimitado, proporcionando maior possibilidade de enfrentar as iniquidades territoriais.

Em síntese, a realização do Planejamento Regional Integrado consiste na elaboração do planejamento por cada ente federado, considerando suas especificidades sociais, econômicas, políticas e sanitárias para além do seu próprio 
território, levando em conta assim, a necessidade da população da sua região de saúde, e não apenas do seu território administrativo.

O planejamento é um importante instrumento para promover a governança das regiões de saúde e deve ser o indutor de políticas para a região, devendo ser realizado de modo regionalizado e integrado, de maneira a promover maior integralidade na oferta de serviços no SUS e governança das regiões.

Portanto, o planejamento estadual de saúde deve ser construído de maneira integrada e ascendente entre os municípios e regiões de saúde, levando em conta que o planejamento é parte do arcabouço legal do SUS, e de acordo com lei 8.080, os planos de saúde serão requisitos necessários para o repasse de recursos, de controle e auditoria (BRASIL, 2009).

Sendo assim as estratégias para consolidação da regionalização em saúde, como o fortalecimento ou construção das ferramentas de planejamento regional como a Programação Pactuada e Integrada (PPI), o Plano Diretor de Regionalização (PDR), o Plano Diretor de Investimentos (PDI), e as Comissões Intergestores Regionais (CIR), deverão ser estabelecidas pelos planos de saúde, demonstrando a intenção de qualificar este processo. Além destes requisitos, o plano de saúde expressa ainda a metodologia na qual o processo de planejamento foi desenvolvido, se ascendente, regionalizado ou não. 


\section{OBJETIVOS}

\subsection{OBJETIVO GERAL}

$>$ O objetivo geral deste estudo foi descrever como o planejamento regional de saúde foi descrito pelos planos estaduais de saúde no Brasil, no quadriênio de 2012 a 2015.

\subsection{OBJETIVOS ESPECÍFICOS}

1 Identificar quais regiões de saúde indicaram a realização de planejamento regional nos respectivos planos estaduais de saúde, relativos ao período 2012-2015;

2 Identificar os atores responsáveis pela realização do planejamento regional, segundo o plano estadual de saúde;

3 Descrever quais são as metodologias de planejamento utilizadas ou desenvolvidas pelas regiões de saúde para realizar o planejamento regional, segundo o plano estadual de saúde; 


\section{METODOLOGIA}

Trata-se de um estudo qualiquantitativo, descritivo, desenvolvido a partir da análise documental e de âmbito nacional, que visou estudar o planejamento regional em saúde descrito nos planos estaduais de saúde, identificando aspectos metodológicos e estruturais quanto à formulação do planejamento regional nas inúmeras regiões de saúde do país.

O estudo foi desenvolvido a partir da análise dos 26 planos estaduais de saúde dos Estados brasileiros com vigência entre os anos de 2012 a 2015. O Distrito Federal (DF) foi excluído pois não há conformação de municípios em seu território. Esse critério foi considerado visto a definição de região de saúde adotada pelo MS que classifica a região como o espaço geográfico contínuo constituído por agrupamento de municípios limítrofes. Portanto, o DF atualmente é considerado como uma única região de saúde que, ao longo de 2015, foi rediscutida para que haja uma nova conformação de regionalização em seu território.

Os planos estaduais de saúde foram coletados a partir da busca ativa nos portais das Secretarias Estaduais de Saúde ou fornecidos pelo Departamento de Articulação Intefederativa da Secretaria de Gestão Estratégica e Participativa do Ministério da Saúde (DAl/SGEP/MS), após solicitação formal pelo pesquisador.

Para a análise dos planos foi construída uma matriz que serviu de roteiro para garantir maior orientação e direcionalidade ao pesquisador (Anexo 01). Para esta análise foi empregada a metodologia de análise de conteúdo proposta por Bardin (2006), com categorias estabelecidas a priori. Foram construídos 17 descritores de análise que formam, em conjunto, 4 categorias de análise denominadas nesse estudo de eixos, definidas previamente pelo pesquisador e apresentadas a seguir: I) EIXO DESCRITIVO; II) EIXO REGIONALIZAÇÃO; III) EIXO PLANEJAMENTO REGIONAL; IV) EIXO PLANEJAMENTO ESTADUAL. 
Abaixo estão descritos os eixos e seus subeixos, de acordo com os achados dos planos estaduais de saúde:

I) EIXO DESCRITIVO;
a) Estado
b) População
c) Número de regiões de saúde do Estado

II) EIXO REGIONALIZAÇÃO;

d) Previsão de metas para a região

e) Fortalecimento da CIR

f) Assinatura do COAP

g) Utilização do PDR

h) Presença de componente regional no plano

i) Indicadores da análise de situação em base municipal, regional ou estadual

j) Previsão para a regionalização

III) EIXO PLANEJAMENTO REGIONAL;

k) Previsão para Planejamento Regional

I) Previsão de ações, metas, diretrizes ou objetivos no âmbito do Planejamento Regional

m) O que foi previsto no âmbito do planejamento regional

n) Responsáveis pelo Planejamento Regional

o) Realização e construção do planejamento regional

IV) EIXO PLANEJAMENTO ESTADUAL;

p) Previsão de fortalecimento da PPI

q) Construção do Plano Estadual

A criação prévia de cada uma das quatro categorias de análise foi guiada pelos objetivos específicos do presente estudo: a primeira categoria - Eixo Descritivo - buscou identificar aspectos que caracterizassem os Estados e as regiões de saúde 
do Brasil visando identificar as informações levantadas pelas outras três categorias de pesquisa com a população estadual e sua quantidade de regiões de saúde.

A segunda categoria - Eixo Regionalização - teve como objetivo identificar os aspectos da regionalização em saúde desenvolvidos ou propostos pelos planos de saúde construídos pelos Estados. Este eixo possibilitou ainda identificar as proposições quanto à assinatura do Contrato Organizativo de Ação Pública (COAP), o fortalecimento da CIR, a utilização do PDR, a construção de indicadores na base regional nos planos, e demais aspectos que são pertinentes ao fortalecimento e evolução das estratégias de regionalização no SUS, de acordo com o objetivo específico 1.

A terceira categoria de análise - Eixo Planejamento Regional - possibilitou o levantamento das informações pertinentes à análise do planejamento regional (PR) nos planos que previram ou realizaram o PR. Esta categoria visou identificar se o plano prevê PR; quais foram as ações, metas, diretrizes e objetivos previstos no âmbito do PR em saúde; quem foram os responsáveis pelo PR no Estado; Como o PR foi realizado; e o que foi proposto pela agenda estratégica dos planos a respeito do PR, de acordo com os objetivos específicos 1, 2, 3 e 4 .

A quarta e última categoria de análise - Eixo Planejamento Estadual - buscou identificar como o plano estadual foi realizado. Com esta análise, foi possível identificar como os Estados construíram seus planos, se de maneira regionalizada ou não. O outro importante indicador desta categoria visou analisar se o plano estadual previa o fortalecimento ou aprimoramento da PPI, o que auxiliou a identificar se a gestão estadual promove a gestão integrada entre os entes federativos ou não, de acordo com os objetivos específicos 1, 2, 3 e 4.

Ainda quanto à análise dos planos, aqueles onde não foram identificados os descritores das categorias apresentados acima, foram classificados e descritos como "Não Informado".

As variáveis quantitativas foram descritas por meio de média, mediana e porcentagens. Para determinação se a mediana de dois ou mais grupos foram diferentes entre si, optou-se pelo teste não paramétrico de Kruskal-Wallis. Optamos por esse teste pois os dados não precisam apresentar distribuição normal para sua 
utilização, visto que utiliza o posto dos valores ao invés dos dados reais para análise, sendo uma alternativa de análise para averiguação da diferença entre grupos em pesquisas, ou para a indicação se os resultados encontrados são apenas variações aleatórias da população de origem (Shikamura, 2008).

Este estudo dispensou aprovação do Comitê Nacional de Ética em Pesquisa (CONEP) por se tratar de análise documental de arquivos públicos. 


\section{MARCO TEÓRICO REFERENCIAL}

A constituição Federal de 1988 estabeleceu em seu artigo de número 196 que a saúde é direito de todos e dever do Estado. Porém, foi em 1990 que a Lei Orgânica da Saúde, ou Lei 8.080/90, foi promulgada constituindo o Sistema Único de Saúde e regulamentando as condições para a promoção, proteção e recuperação da saúde. A lei 8.080/90 estabelece ainda os princípios do SUS, que dentre eles encontram-se os princípios da universalidade, integralidade, igualdade e descentralização político-administrativa (BRASIL, 1988; 1990; PAIM, 2009).

Hoje, o SUS é reconhecido como o maior sistema de saúde de caráter universal do mundo, o que representa uma grande responsabilidade política e administrativa para os gestores do SUS e para os dirigentes deste sistema que já possui 28 anos e tem o desafio de cobrir uma população de proporções continentais.

Devemos levar em conta ainda que a consolidação deste sistema continua em constante construção, uma vez que muitos desafios são colocados dia-após-dia na efetivação do SUS, como; o sub-financiamento, a judicialização, a efetivação da participação do controle social, o acesso universal aos serviços de saúde, a consolidação das redes de atenção integradas e regionalizadas, dentre outras (PAIM, 2009).

Portanto, faz-se necessário investigar alguns destes desafios em busca de respostas e soluções que contribuam com a efetividade da atenção integral à saúde da população brasileira através do SUS. Nesta perspectiva, a regionalização do sistema de saúde é entendida como uma importante estratégia para consolidação da integralidade no SUS.

A regionalização é uma forma de organizar um território geográfico delimitado de maneira qual serviços, recursos, sistemas e processos possam ser organizados de maneira qual sua oferta e disposição venham a favorecer uma população com serviços que atendam a todas as suas necessidades. Quando falamos em regionalização, associamos o conceito à possibilidade de proporcionar a facilidade 
de acesso, racionalização da oferta, processo de avaliação, equidade, universalidade, e principalmente integralidade (GIL, 1995).

Nos anos 1980, o conceito de regionalização apareceu como “... um processo de descentralização como o objetivo de hierarquizar, disciplinar e operar uma rede de serviços de saúde sob a forma de complexidade crescente, de acordo com as necessidades da população. " (BRASIL, 1980).

Nota-se que os dois conceitos trazem a construção de redes de atenção e planejamento em saúde como o seu objetivo central, mas também há uma certa evolução nos conceitos de organização e definição destas regiões, uma vez que na definição de 2011 são consideradas as identidades culturais, econômicas e sociais e de redes de comunicação e infraestrutura de transportes compartilhados.

\subsection{ASPECTOS HISTÓRICOS DA REGIONALIZAÇÃO EM SAÚDE}

Hoje, muito se discute sobre o processo de regionalização do SUS, e defende-se, inclusive, o mote "regionalização é o caminho". No entanto, a importância da regionalização para o SUS é algo antigo e sua implementação vem avançando lentamente ao longo da história da política nacional de saúde, apesar das normativas que estabelecem e regulamentam o processo de regionalização terem avançado desde a constituição de 1988.

Na Inglaterra, o conceito de regionalização dos serviços de saúde já havia sido discutido em 1920 por Bertrand Dawson, que era membro do Conselho Consultivo Médico do Ministério da Saúde da Inglaterra. Na época, Dawson propunha a regionalização dos serviços no objetivo de contestar o modelo médico Flexneriano emergente no momento. Sua proposta era de que a medicina preventiva e a curativa não poderia ser separadas uma vez que todos os planos de serviços médicos deveriam ser estritamente coordenados. Dawson defendia também que quaisquer planos de serviços médicos deveriam ser acessíveis a todas as classes da comunidade. Sua contribuição, no entanto, propõe que a regionalização é uma forma de coordenar os aspectos preventivos e terapêuticos em uma zona específica (DOWNSON, 1920; GIL, 1995). 
Já no Brasil, a regionalização em saúde vem sendo discutida desde a década de 60. O relato mais antigo é registrado em 1963, durante a realização da III Conferência Nacional de Saúde, onde os sanitaristas da época já propunham a regionalização, hierarquização e descentralização como medidas para a reorientação da política nacional de saúde (GIL, 1995).

Ao final da década de 60 estes ideais já haviam sido pervertidos para atuar de forma a contribuir com a lógica médico-assistencial-privatista, tomando caminhos muito diferentes àqueles que defendiam os sanitaristas desenvolvimentistas na III Conferência Nacional de Saúde (LUZ ,1986).

Já na década de 70, com o fortalecimento e difusão do planejamento na América Latina a partir do método CENDES/OPS, as Secretarias Estaduais de Saúde passam a desenvolver a programação em saúde em seus territórios utilizando o conceito de áreas programáticas, propostas pelo método de planejamento. A partir desta tendência, os serviços de saúde passam a se organizar por meio da desconcentração administrativa e da utilização de estruturas regionalizadas, de forma qual as áreas urbanas periféricas e rurais das cidades pudessem estar inseridas na programação da oferta de serviços de saúde (MENDES, 1987).

Em 1975, a fim de contribuir com o processo de planejamento e programação em saúde instaurado no momento, a $\mathrm{V}$ Conferência Nacional de Saúde considerou a relevância da construção e organização das áreas programáticas, e as definiu como "região, conjunto de regiões ou de microrregiões, municípios ou conjunto de municípios para os quais se estabelece um diagnóstico e uma programação em saúde" (BRASIL, 1975).

Ainda durante a década de 70 a desconcentração administrativa e a descentralização dos serviços de saúde eram as principais estratégias defendidas e que mais avançavam. É nesse sentido, que em 1977, durante a VI Conferência Nacional de Saúde foram discutidas as ações do PIASS - Programa de Interiorização das Ações de Saúde e de Saneamento. Este programa tinha como objetivo ampliar a cobertura e a oferta de serviços de saúde (GIL,1995; BRASIL, 1977). 
Mesmo as ações de municipalização e descontração administrativas sendo o foco das políticas da época, em 1978, durante a Conferência de Alma Ata, a regionalização foi pactuada como um dos princípios da Atenção Primária em Saúde. E em 1980, durante a VII Conferência Nacional de Saúde, as discussões sobre a regionalização na saúde ganham força, o conceito de regionalização na saúde é definido, e a estratégia é retomada como proposta para organizar as ações e serviços de saúde (BRASIL, 1980; GIL, 1995).

De acordo com Gil (1995), é a partir daí que a regionalização dos serviços de saúde é incorporada nas diretrizes gerais das propostas governamentais de reorganização do setor saúde. No final da década de 80 , com a pressão realizada pelo movimento sanitário e a luta pelos diretos sociais, a nova constituição brasileira promulgada em 1988 estabelece o SUS - Sistema Único de Saúde - que traz como uma de suas diretrizes a regionalização.

No entanto, apesar de estabelecido pelas diretrizes do SUS e pela Constituição Federal, o processo de regionalização ainda não havia sido implantado de fato. É somente em 2002, com a edição da NOAS - Norma Operacional de Assistência à Saúde que o processo de regionalização no SUS passa a ter uma estratégia de implantação (VIANA, 2011).

A NOAS propôs que as regiões de saúde fossem organizadas pelos Estados a partir do PDRI - Plano Diretor de Regionalização e Investimentos. Nesse documento as regiões de saúde estariam caracterizadas e sua organização deveria contribuir com a efetivação das Redes Regionalizadas e Integradas de Saúde. A NOAS propôs ainda que fossem estabelecidos os CGR - Colegiados de Gestão Regional, que atuariam como instância de governança no âmbito das regiões de saúde.

Em 2006, a dição do Pacto Pela Saúde reforçou as diretrizes do processo de regionalização no SUS e mais recentemente, no ano de 2011, foi sancionado o Decreto 7.508, que depois de 20 anos veio regulamentar a Lei 8.080. O Decreto dispõe sobre a organização do SUS, o planejamento da saúde, a assistência à saúde e a articulação interfederativa. O Decreto, quanto à articulação interfederativa, dispõe sobre a organização das instâncias de governança no SUS, o processo de planejamento estratégico, a RENAME - Relação Nacional de Medicamentos 
Essenciais, institui o COAP - Contrato Organizativo de Ação Pública, e a RENASES - Relação Nacional de Ações e Serviços Essenciais (BRASIL, 2011).

Dentre as contribuições do Decreto, o COAP é uma das estratégias que mais influenciaram no processo de regionalização do SUS, sendo o COAP por si só, uma estratégia particular de organizar e orientar as regiões de saúde no Brasil.

Enquanto na Europa a regionalização da saúde já vem sendo discutida há quase um século, no Brasil, por mais tardio que tenha sido a adoção da regionalização em nossas políticas de saúde, podemos considerar que ao menos as normativas que corroboram com a construção da regionalização da saúde vem avançando.

De acordo com Lenir Santos (2015), por muito tempo discutimos a municipalização e a descentralização - por quase toda a década de 90 - acreditando que a municipalização seria o caminho. No entanto, hoje reconhecemos a necessidade de se regionalizar a descentralização, levando em conta que atualmente consideramos que "regionalizar é o caminho".

Contudo, se hoje reconhecemos que regionalizar é o caminho e consideramos que as políticas e as normativas que estabelecem o processo de regionalização da saúde avançaram, por que a regionalização da saúde ainda não funciona e por que de todo esse atraso na implantação das redes regionalizadas e integradas no SUS?

Podemos apontar alguns motivos ou entraves ao atraso na implementação da regionalização no SUS. Primeiramente, as ambiguidades conceituais do processo de regionalização; em segundo lugar, os impactos na mudança dos sistemas de governança e poder dentro do SUS; e em terceiro lugar, a conformação estrutural do governo de caráter paternalista e patrimonialista (BRASIL, 2014).

As ambiguidades conceituais do processo de regionalização se referem às limitações que eram impostas ao modelo de região que havia sido proposto inicialmente, onde a região era definida de forma exclusivamente geográfica e o seu objetivo era o de racionalizar recursos (GIL, 1995). 
Essa lógica limitada e simplificada de região foi desconstruída e o conceito de regionalização proposto em 2011 pela Resolução CIT n 29 foi construído com elementos que consideram as "...identidades culturais, econômicas e sociais e de redes de comunicação e infraestrutura de transportes compartilhados, na finalidade de integrar a organização, o planejamento e a execução de ações e serviços de saúde "(BRASIL, 2011).

Essas ambiguidades conceituais anteriormente estabelecidas derivaram das influências que o modelo biologicista determinava como padrão na época. No entanto, de acordo com Gil (1995), um conceito de regionalização que seja compatível ao modelo atual deve priorizar a qualidade, a equidade e a humanização da assistência.

O impacto do sistema de governança e poder no SUS apresenta-se como outro grande desafio ao processo de regionalização. A implementação das regiões de saúde no território brasileiro depende da mobilização de novos atores, integração mútua entre os entes federados, compartilhamento de recursos materiais, humanos e financeiros, e gestão dos complexos regionais. Todas essas características apontam para uma mudança no processo de poder e governança no sus, pois para efetiva-las necessitamos de novas conformações políticas, organizacionais, normativas e ideológicas (VIANA, 2011).

De acordo com Lenir Santos (2015) "o sus é essencialmente regionalizado por disposição constitucional e não por escolha dos agentes públicos". Esta colocação expressa bem o cenário enfrentado pela regionalização no SUS. Romper com esses paradigmas políticos onde os dirigentes da saúde em suas distintas esferas de governo estão tão confortáveis com o poder e a governança que exercem que acabam por não aderir às estratégias de regionalização que de toda forma determinarão novas conformações políticas e governamentais alterando as estruturas de poder (SANTOS, 2015).

Por fim, Gastão Wagner de Sousa (2015) aponta que a própria conformação estrutural do governo que é de caráter paternalista, patrimonialista e clientelista é que muito influencia a nossa estrutura de poder e governança no SUS. Essa característica do Estado brasileiro afeta diretamente a forma como se faz a gestão e a governança no sistema de saúde (CAMPOS, 2015). 
No lugar de serem desenvolvidas e cumpridas as políticas de Estado, a gestão local possui muita autonomia e poder para implementar políticas governamentais e concentrar seus esforços apenas no objetivo de cumpri-las. Cabe ainda a esse processo a autonomia dos gestores em aderir ou não ao COAP, que tendo sido lançado em 2011, até o ano de 2015 apenas dois Estados aderiram ao contrato (BRASIL, 2015).

Por fim, a proposta de Gastão Wagner para que a regionalização do SUS tenha êxito, parte inicialmente de uma reforma na gestão pública que promova a diminuição da autonomia do poder executivo, criação de novas personalidades jurídicas, e diminuição da dependência que as políticas nacionais têm de serem executadas pelo poder executivo (CAMPOS, 2015).

\subsection{O PROCESSO DE PLANEJAMENTO INTEGRADO E REGIONALIZADO NO SUS}

"Planejar consiste basicamente em decidir com antecedência o que será feito para mudar condições insatisfatórias no presente ou evitar que condições adequadas venham a deteriorar-se no futuro."

(CHORNY, 1998)

De acordo com Matus (1987), o planejamento é um cálculo situacional sistemático que relaciona o presente com o futuro e o conhecimento com a ação. No SUS, o planejamento em saúde é um instrumento essencial de gestão estabelecido pela Constituição Federal de 1988, que em síntese, se dará por meio da elaboração dos Planos de Saúde, das Programações Anuais de Saúde e dos Relatórios de Gestão nas três esferas de gestão.

O Sistema de Planejamento do SUS (2009) define o Plano de Saúde como: "O instrumento que a partir de uma análise situacional, apresenta as intenções e os resultados a serem buscados no período de quatro anos expressos em objetivos, diretrizes e metas. "

Os planos de saúde elaborados por cada esfera de governo apontarão as políticas de saúde e os compromissos firmados por cada um destes entes a partir 
das agendas estratégicas de cada plano. Neste sentido, os planos de saúde serão a base para a execução, monitoramento e avaliação da gestão do SUS em cada esfera de governo (BRASIL, 2009).

Em 2015 o Ministério da Saúde e a Fundação Oswaldo Cruz lançaram em conjunto o Manual de Planejamento no SUS. O objetivo desta publicação foi atualizar os gestores do SUS com um documento técnico que possibilite sua orientação e apropriação dos mecanismos de planejamento, que após a edição do decreto $n^{\circ} 7.508$ e da Lei complementar $n^{\circ} 141$ receberam inovações políticas e administrativas, que incluem o planejamento de âmbito regional.

A princípio, o documento denomina o planejamento no âmbito das regiões de saúde como planejamento regional integrado. Este processo deverá ser o ordenador das ações, estratégias e políticas de saúde definidas pelos planos de saúde e programações anuais dos entes federativos que compõem uma determinada região.

O planejamento regional integrado deverá ser coordenado pela gestão estadual, por meio da secretaria estadual de saúde, envolvendo todos os municípios da região. No entanto, a responsabilidade da pactuação, monitoramento e avaliação do processo será das CIR's, que representam os atores político-adminstrativos das regiões de saúde que deverão possuir governança sobre o processo de planejamento regional (BRASIL, 2011; 2015).

Portanto, o Manual de Planejamento no SUS atribui a realização do planejamento regional à composição original do COAP, que é o instrumento empregado pelo decreto $\mathrm{N}^{\circ} 7.508$ para promover a contratualização das responsabilidades sanitárias pactuadas entre as regiões de saúde e os entre federativos que a compõe. No contrato, o planejamento regional deverá expressar:

- A identificação das necessidades de saúde da população e a análise da situação de saúde do território;

- As diretrizes, os objetivos plurianuais e as metas anuais, bem como os prazos de execução, indicadores e responsabilidades dos entes federados; 
- A Programação Geral das Ações e Serviços de Saúde, incluindo os componentes de promoção, proteção, recuperação e reabilitação em saúde, (assistência, vigilância em saúde - epidemiológica, sanitária e saúde ambiental - e assistência farmacêutica), conforme disposto na Renases e na Rename;

- As responsabilidades pelo financiamento.

Ainda de acordo com 0 manual, são definidos cinco passos para 0 desenvolvimento do planejamento regional integrado, são eles:

1. Definição das regiões de saúde;

2. Elaboração do mapa da saúde e da análise situacional;

3. Definição das responsabilidades sanitárias e das intervenções a partir das diretrizes, objetivos, metas e indicadores;

4. Programação Geral das Ações e Serviços de Saúde (PGASS);

5. Definição das responsabilidades orçamentárias e financeiras.

Em síntese, os cinco passos consistem em: definir as regiões de saúde de acordo com suas especificidades e respeitando a conformação de região estabelecida pelo Decreto $n^{\circ}$ 7.508; construção da análise de situação por meio do mapa da saúde, que consiste em um importante instrumento para análise da situação sanitário de um determinado território ou região de saúde levando em conta seu perfil sócio-político-sanitário; definir as diretrizes, objetivos, metas e indicadores que deverão ser alcançados pelos entes federados que compõe as regiões de saúde por meio da gestão compartilhada e solidária; elaboração da PGASS, que deverá ser considerado como um momento do processo de planejamento regional integrado e terá a função de harmonizar as diretrizes, objetivos, metas e indicadores com os recursos físicos e financeiros necessários para seu alcance; e por último, a definição das responsabilidades orçamentárias e financeiras que serão organizadas por meio dos instrumentos de planejamento local como a Programação Anual de Saúde, Planos de Ação das Redes Estratégicas, definição dos recursos da vigilância, atenção básica e etc. 


\section{RESULTADOS}

Para a exposição dos resultados deste estudo optou-se por descrever os achados dos 4 Eixos de pesquisa a partir da descrição de cada uma de suas respectivas subcategorias. A seguir estão descritas as 17 subcategorias definidas previamente.

\subsection{DESCRIÇÃO DOS RESULTADOS POR VARIÁVEIS DA MATRIZ DE ANÁLISE:}

I) EIXO DESCRITIVO

\section{Estado}

A partir da análise documental composta por leitura flutuante e busca de palavras foram analisados os planos estaduais dos 26 Estados brasileiros, exceto 0 DF. Pela análise foram identificados 16 Estados que em seus planos mencionam o planejamento regional ou integrado, e 10 Estados que não mencionam essas palavras em seu texto e mesmo a partir da leitura em profundidade não demonstravam a realização ou intenção de construir ou apoiar o planejamento integrado e regionalizado.

Os Estados que mencionaram, demonstraram intenção, apoio ou realização do planejamento regional foram: Acre, Alagoas, Amazonas, Bahia, Ceará, Maranhão, Mato Grosso do Sul, Minas Gerais, Pará, Pernambuco, Rio de Janeiro, Rio Grande do Norte, Rio Grande do Sul, Roraima, Sergipe e Tocantins.

E os Estados que não apresentaram, ou não mencionaram o planejamento regional no plano estadual foram: Amapá, Espírito Santo, Goiás, Mato Grosso, Paraíba, Paraná, Piauí, Rondônia, Santa Catarina, São Paulo. 


\section{População (IBGE)}

A segunda variável analisada se referiu à população estadual. Entre os Estados que apresentaram planejamento integrado e regionalizado em seu texto, os Estados de maior população são os de Minas Gerais com 19.597.330 de habitantes, Rio de Janeiro com 16.112.637 de habitantes, e o Estado da Bahia com 14.021.432 de habitantes. Já os Estados de menor população, encontra-se Roraima com 450.479 habitantes, Amapá com 669.526 habitantes, e o Estado do Acre com 746.375 habitantes.

Quanto aos Estados que não fizeram menção ao planejamento integrado e regionalizado encontra-se São Paulo como o de maior população, com 41.262.199 de habitantes, seguido do Estado do Paraná com 10.440.000 de habitantes, e Santa Catarina com 6.248.436 de habitantes. Quanto aos Estados de menor população estão o Amapá com 669.526 habitantes, Rondônia com 1.560 .501 habitantes, e Mato Grosso com 3.033.991 de habitantes.

Vale ressaltar que o Estado de São Paulo, embora não reconheça explicitamente em seu plano a construção do planejamento regionalizado, o mesmo apresentou grande participação regional e das instâncias regionais na elaboração do plano estadual. Esta observação pôde ser realizada durante a análise do Eixo IV deste estudo que identificou a participação regional na elaboração dos planos estaduais de saúde.

Portanto, é possível observar que há uma relação entre a população dos Estados com a presença do planejamento integrado e regionalizado nos planos de saúde, tendo em vista que os Estados de maior população mencionaram com maior frequência o planejamento integrado e regionalizado em seus planos de saúde, como se pode observar na Tabela 01.

Embora o Estado de São Paulo, não tenha mencionado a realização do Planejamento Regional em seu plano de saúde o Estado apresentou grande participação das regiões de saúde e das instâncias regionais na elaboração do seu plano estadual. 


\section{Número de Regiões de Saúde nos Estados}

A tabela a seguir apresenta a relação entre os Estados brasileiros, que na análise documental dos planos, apresentaram ou não, o planejamento regional em seu texto com a quantidade de suas respectivas regiões de saúde.

Tabela 01 - Relação entre Estados brasileiros com sua população e respectivas regiões de saúde.

\begin{tabular}{|c|c|c|c|}
\hline Estado & $\begin{array}{c}\text { PR no } \\
\text { plano }\end{array}$ & $\begin{array}{c}\text { População } \\
\text { (IBGE 2010) }\end{array}$ & $\begin{array}{c}\mathbf{N}^{\circ} \text { Regiões de } \\
\text { Saúde 2014 }\end{array}$ \\
\hline Minas Gerais & SIM & 19.597 .330 & 77 \\
\hline São Paulo & NAO & 41.262 .199 & 63 \\
\hline Rio Grande do Sul & SIM & 10.733 .030 & 30 \\
\hline Bahia & SIM & 14.021 .432 & 28 \\
\hline Paraná & NAO & 10.440 .000 & 22 \\
\hline Ceará & SIM & 8.452 .381 & 22 \\
\hline Maranhão & SIM & 6.569 .683 & 19 \\
\hline Goiás & NÃO & 6.003 .788 & 17 \\
\hline Santa Catarina & NAO & 6.248 .436 & 16 \\
\hline Paraíba & NAO & 3.766 .528 & 16 \\
\hline Mato Grosso & NÃO & 3.033 .991 & 16 \\
\hline Pará & SIM & 7.443 .904 & 13 \\
\hline Pernambuco & SIM & 8.796 .448 & 12 \\
\hline Piauí & NAO & 3.118 .360 & 11 \\
\hline Alagoas & SIM & 3.120 .494 & 10 \\
\hline Rio de Janeiro & SIM & 16.112 .637 & 9 \\
\hline Amazonas & SIM & 3.807 .923 & 9 \\
\hline Rio Grande do Norte & SIM & 3.168 .027 & 8 \\
\hline Tocantins & SIM & 1.800 .000 & 8 \\
\hline Sergipe & SIM & 2.068 .031 & 7 \\
\hline Rondonia & NAO & 1.560 .501 & 6 \\
\hline Espírito Santo & NÃO & 3.512 .672 & 4 \\
\hline Mato Grosso do Sul & SIM & 2.477 .504 & 4 \\
\hline Acre & SIM & 746.375 & 3 \\
\hline Amapá & NAO & 669.526 & 3 \\
\hline Roraima & SIM & 450.479 & 2 \\
\hline TOTAL & & 188.981 .679 & 435 \\
\hline
\end{tabular}

Fonte: Elaboração própria com base nos dados do IBGE e SGEP/MS. 
De acordo com a tabela acima, os Estados com a maior quantidade de regiões de saúde são Minas Gerais (77), São Paulo (63), Rio Grande do Sul (30) e Bahia (28). Entre estes quatro Estados, apenas São Paulo não mencionou em seu texto base o planejamento integrado e regionalizado apesar de ter realizado o planejamento estadual contando com grande participação das instâncias regionais. Quanto aos Estados com a menor quantidade de regiões de saúde, observa-se que o número de Estados que mencionam o planejamento integrado e regionalizado em seu texto não está constante.

Para verificar se houve associação entre o número de regiões e a presença do Planejamento Regional nos planos, utilizou-se o teste de Kruskal-wallis, conforme descrito na metodologia. Para compor a tabela, o dado foi desagregado em três grupos de Estados definidos de acordo com a sua quantidade de regiões de saúde: maior que 20 regiões de saúde; entre 10 e 19 regiões de saúde; e menor que 10 regiões de saúde.

\section{Tabela 02 - Número de regiões de saúde nos Estados e a presença do PR nos planos de saúde, Brasil, 2012-2015.}

\begin{tabular}{c|c|c|c|c|c|c}
\hline \multirow{2}{*}{ N de regiões de saúde } & \multicolumn{2}{|c|}{ PR no plano (SIM } & \multicolumn{2}{|c|}{ PR no plano (NAO) } & \multicolumn{2}{|c}{ Total } \\
\cline { 2 - 7 } & $\mathbf{n}$ & $\%$ & $\mathbf{n}$ & $\%$ & $\mathbf{n}$ & $\%$ \\
\hline Maior que 20 & 4 & 15,38 & 2 & 7,69 & 6 & 23,08 \\
\hline Entre 10 e 19 & 4 & 15,38 & 5 & 19,23 & 9 & 34,62 \\
\hline Abaixo de 10 & 8 & 30,77 & 3 & 11,54 & 11 & 42,31 \\
\hline Total & 16 & 61,54 & 10 & 38,46 & 26 & 100 \\
\hline $\mathbf{p = 0 , 5 4 8} \mathbf{p = 0 , 4 2 9 1}$ & & & & & &
\end{tabular}

Fonte: Própria

A partir da análise da Tabela 2, percebeu-se que a diferença de ocorrência de PR nos planos de saúde não se diferiu entre os grupos. Apesar dos Estados com menor número de regiões de saúde concentrarem maior proporção de citações ao 
$\mathrm{PR}$, essas não podem ser compreendidas como não aleatórias e realmente associadas ao número de regiões de saúde.

Quando utilizado o mesmo método para identificar se houve associação entre a população dos Estados e a presença do planejamento regional nos planos de saúde, obteve-se os seguintes resultados.

Tabela 03 - População dos Estados e a presença do PR nos planos de saúde, Brasil, 2012-2015.

\begin{tabular}{c|c|c|c|c|c|c}
\hline \multirow{2}{*}{ População } & \multicolumn{2}{|c|}{ PR no plano (SIM) } & PR no plano (NÃO) & \multicolumn{2}{c}{ Total } \\
\cline { 2 - 7 } & $\mathbf{n}$ & $\%$ & $\mathbf{n}$ & $\%$ & $\mathbf{n}$ & $\%$ \\
\hline 7 milhões ou mais & 7 & 26,92 & 2 & 7,69 & 9 & 34,62 \\
\hline Entre 3 e 7 milhões & 4 & 15,38 & 6 & 23,08 & 10 & 38,46 \\
\hline Menor que 3 milhões & 5 & 19,23 & 2 & 7,69 & 7 & 26,92 \\
\hline Total & 16 & 61,54 & 10 & 38,46 & 26 & 100 \\
\hline $\mathbf{p}=\mathbf{0 , 3 2 9 0} \mathbf{p = 0 , 2 0 9 4}$
\end{tabular}

Fonte: Própria

Pela análise da Tabela 3, observou-se que houve maior proporção de ocorrência de PR em planos estaduais de saúde de Estados com mais de 7 milhões de habitantes, entretanto, essa diferença também não pode ser definida como estatisticamente significante, a partir do teste não paramétrico de Kruskal-Wallis.

II) EIXO REGIONALIZAÇÃO

\section{Previsão de metas para a região}

Este descritor buscou identificar em quais Estados as metas propostas nas agendas estratégicas eram previstas para a região de saúde. Como resultado, foi identificado que em 24 planos estaduais as metas na agenda estratégica foram 
previstas para a região, os outros 2 planos estaduais não informaram ou não apresentaram metas para a região de saúde.

Dentre os 24 planos estaduais informados acima, 6 deles apresentaram até cinco metas regionais em toda a agenda estratégica, um apresentou metas regionais apenas para os objetivos que envolvem o tema da regionalização, e em outro foi abordada metas regionais apenas para a construção e instalação de redes temáticas. Os demais planos estaduais apresentaram outras metas para a região.

Observa-se ainda que entre todos os planos analisados a sua maioria apresenta metas regionais voltadas para construção ou implementação das redes temáticas ou das Redes Regionalizadas de Atenção à Saúde (RRAS).

\section{Fortalecimento da CIR}

Dentre os 26 planos analisados, 15 apresentaram diretrizes, objetivos ou metas que previam o fortalecimento das CIR, 8 não apresentaram a intenção de fortalecer as CIR, e 3 não informaram devido inexistência de diretrizes objetivos ou metas na agenda estratégica.

Dentre os planos estaduais que previram diretrizes, objetivos ou metas no âmbito das CIR, foram encontradas as seguintes intenções:

- Assessorar e participar na implantação e implementação regionais nas CIR;

- Aprimorar o processo de negociação e pactuação das CIR;

- Fortalecimento da atenção básica na CIR;

- Realizar reuniões da CIR;

- Promover qualificação das CIR;

- Melhoria da qualidade da CIR;

- Implementar equipe de apoio nas CIR;

- Promover apoio técnico e financeiro;

- Participar das reuniões da CIR;

- Debater o papel do controle social nas CIR; 
- Apoiar o funcionamento das CIR;

- Implementar mais CIR;

- Fortalecimento e qualificação das CIR;

- Apoiar a estruturação das CIR;

- Reconhecer as CIR.

A partir da análise das intenções acima apresentadas pelos planos estaduais, observa-se que há grande intenção em fortalecer as CIR nos Estados.

\section{Assinatura do COAP}

Ao analisar as diretrizes, objetivos e metas dos 26 planos estaduais foram identificados em 17 deles a intenção de assinar o COAP, implementa-lo em 100\% das regiões de saúde do Estado ou de realizar atividades para a sua adesão. Em 5 planos estaduais não foram previstas ações que propõem a assinatura do COAP, e em 4 planos estaduais não foram identificadas ações e metas desta natureza uma vez que estes planos não apresentaram agenda estratégica com diretrizes, objetivos, ações ou metas.

\section{Utilização do PDR}

O Plano Diretor de Regionalização é uma ferramenta de gestão essencial para a organização das regiões de saúde dos Estados, com isso organizar e orientar a construção e atualização dos PDR's nos Estados torna-se uma ação fundamental para a organização das regiões e das redes regionalizadas.

Durante a análise dos planos estaduais foram identificados 18 planos estaduais de saúde que utilizam o PDR para sua conformação de regiões e 8 planos estaduais não apresentaram informações quanto ao PDR em todo o seu texto base ou em sua agenda estratégica. 


\section{Presença de componente regional no plano}

O componente regional do plano é o capítulo, fragmento ou parte do texto base de um plano estadual de saúde que se dedica a apresentar as informações referentes às estratégias da política de regionalização que em grande parte dos planos identificam como o Estado tem aplicado e gerenciado a política nacional de regionalização em seu território. Nesse campo é possível analisar como o Estado vem gerenciando suas regiões de saúde, se aplicam o planejamento regional, como organizam as Redes de Atenção à Saúde (RAS) em seu território e até mesmo se pretendem ou não firmar compromissos com o COAP.

$\mathrm{Na}$ análise deste componente foram identificados que 17 planos estaduais possuem o componente regional em sua estrutura, 8 não, e 1 não apresentou informações suficientes para o preenchimento das informações.

\section{Indicadores da análise de situação em base Municipal, Regional ou Estadual}

A análise de situação é um elemento fundamental do plano de saúde, é nela que todos os indicadores estaduais são apresentados no objetivo de realizar um levantamento sobre a situação de saúde do Estado. Estes indicadores geralmente são apresentados nos planos de saúde por bases estaduais, municipais ou regionais.

A tabela abaixo apresenta a frequência com que os planos estaduais organizam seus indicadores da análise de situação, se na base estadual, municipal ou regional. 
Tabela 04 - Quantidade de planos com indicadores da análise de situação apresentados na base municipal, regional ou estadual

\begin{tabular}{|c|c|}
\hline $\begin{array}{c}\text { INDICADORES NA BASE MUNICIPAL, REGIONAL OU } \\
\text { ESTADUAL }\end{array}$ & $\mathbf{N}^{\circ}$ \\
\hline Apenas estadual & 1 \\
\hline Apenas municipal & 1 \\
\hline Apenas regional & 3 \\
\hline Estadual e municipal & 6 \\
\hline Estadual e regional & 10 \\
\hline Estadual, municipal e regional & 3 \\
\hline Não identificado & 2 \\
\hline TOTAL & $\mathbf{2 6}$ \\
\hline
\end{tabular}

Fonte: Própria

Dentre os planos analisados, 16 apresentaram indicadores definidos na base regional, 8 não, e 2 não forneceram informações suficientes para que fossem identificadas as informações necessárias para esta análise.

Para esta análise, os planos que apresentaram ao menos um indicador na base regional, municipal ou estadual foram classificados como tal, sendo necessário cada plano apresentar um indicador em uma determinada base para que fosse classificado como um plano que apresente indicadores nestas categorias.

Em alguns planos foram identificadas três considerações importantes: a) os indicadores na base regional eram exclusivos para um determinado nível de atenção, como a atenção básica; b) eram identificados indicadores nas três bases, mas suas diretrizes, objetivos e metas eram organizadas para atender indicadores regionais; c) a análise de situação encontrada apresentava todos os seus indicadores na base regional, especialmente os epidemiológicos. 


\section{Previsão para a regionalização}

Para analisar o que cada Estado prevê para no âmbito da regionalização foram identificadas as ações e metas estabelecidas pelos 26 planos estaduais que possuíam o objetivo de desenvolver processos relacionados a regionalização em saúde. Com este objetivo foram identificadas as Diretrizes, Objetivos, Ações, Metas e Estratégias voltadas para a regionalização que cada plano estadual possuía.

A seguir estão descritas e sintetizadas cada uma das categorias das agendas estratégicas que possuíam processos no âmbito da regionalização.

\section{Diretrizes}

- Implementação de novo modelo de gestão e instrumentos de relação federativa;

- Implantar a Rede de Atenção à Urgência e Emergência nas Regiões Ampliadas de Saúde do Estado;

- Fortalecimento do desenvolvimento regional da atenção à saúde;

- Consolidação da regionalização no Estado por meio das redes regionalizadas de atenção à saúde;

- Formação adequada dos profissionais do sus para atuar de acordo com os princípios da regionalização e descentralização da saúde;

- Reorganização dos Serviços de Média Complexidade, com processo de descentralizar os serviços para que se possa montar uma rede regionalizada;

- Instrumentalizar a gestão para desenvolver ações de investimento e custeio do Sistema Estadual de Saúde;

- Aperfeiçoamento da gestão na saúde conforme as diretrizes do Decreto oo 7.508 de 28 de junho de 2011;

- Assegurar uma gestão eficiente e efetiva do sistema de saúde, fortalecendo a descentralização, a regionalização e o controle social, com um planejamento integrado. (BA) 


\section{Objetivos}

- Implantação de novo modelo de gestão e de instrumentos de relação federativa;

- Inserção dos hospitais na rede regionalizada de atenção à saúde, por meio da reorganização da atenção hospitalar em cada Região;

- Apoiar técnica e financeiramente as unidades especializadas de referência regional;

- Implementar as ações realizadas pelos Centros Regionais Especializados;

- Capacitar às equipes regionais;

- Fortalecimento da gestão regional;

- Monitorar a concretização dos compromissos assumidos nos COAP;

- Aperfeiçoar e fortalecer a gestão descentralizada e regionalizada do SUS;

- Consolidar a oferta da atenção hospitalar nos polos regionais;

- Aumento da Taxa de Resolubilidade Regional;

- Fortalecimento da CIB Estadual e das 22 CIB's Regionais;

- Consolidar e implementar o processo de regionalização no Estado;

- Monitorar e avaliar a organização das redes regionalizadas e hierarquizadas de atenção no Estado;

- Consolidação a ampliação da descentralização das ações de vigilância sanitária, com foco na regionalização;

- Fortalecer a Gestão descentralizada, aprimorando os processos de negociação e pactuação nas Comissões Intergestores Regionais - CIR e CIB;

- Implantar a regionalização em saúde;

- Garantir o acesso aos serviços de saúde de forma integral e regionalizada, com qualidade e eficiência ao cidadão;

- Fortalecer a gestão cooperada e regionalizada do SUS;

- Estimular, apoiar e assessorar tecnicamente as SMS na formalização do COAP - Contrato Organizativo de Ação Pública de Saúde;

- Assegurar o cumprimento das metas a serem pactuadas no COAP e no PPA;

- Aperfeiçoar a Programação Pactuada e Integrada da assistência como instrumento organizador do acesso, nas regiões de saúde e nas linhas de atenção prioritárias. 


\section{Ações}

- Implantar o Plano de Fortalecimento dos Núcleos de Gestão Regional das Unidades Regionais de Saúde;

- Promover anualmente a participação de Gestores Municipais e da SES em eventos de relevância para Gestão e Regionalização da Saúde;

- Realizar $100 \%$ das reuniões Ordinárias e Extraordinárias das Comissões Intergestores Regionais;

- Realizar bianualmente 01 Evento Estadual envolvendo gestores municipais, controle social e técnicos estaduais com ênfase na Regionalização da Saúde;

- Estabelecer as responsabilidades na gestão compartilhada entre os entes federativos;

- Revisar o desenho da regionalização da assistência;

- Elaborar análise situacional de saúde por Região de Saúde;

- Fortalecer a Comissão Intergestores Bipartite e Comissões Intergestores Regional;

- Instalar 09 CIR em nove regiões de saúde;

- Realizar curso de atualização para as secretarias executivas das CIR implantadas;

- Criar na estrutura organizacional da SES as CIR e os escritórios regionais;

- Apoiar a estruturação de $100 \%$ das Comissões Intergestoras Regionais (CIR) no Estado;

- Estimular e apoiar a organização de consórcios públicos em $100 \%$ das Regiões de Saúde do Estado;

- Fortalecendo a regionalização da saúde;

- Promover a assinatura dos Contratos Organizativos de ação pública com definição de responsabilidade de todos os entes federados em $100 \%$ das Regiões de saúde;

- Reconhecer e fortalecer as instâncias legítimas de discussão e pactuação do SUS, como Câmaras Técnicas, CIR e CIB;

- Qualificação e Monitoramento da Gestão Regional de Saúde;

- Acompanhamento, Monitoramento e Avaliação do Pacto pela Saúde; 
- Revisar o Plano Diretor de Regionalização-PDR para implantação das Regiões de Saúde de acordo com Decreto no 7.508/2011.

\section{Metas}

- Implantar Redes de Atenção ao Idoso em todas as Regiões Ampliadas de Saúde;

- Garantir que $100 \%$ das regiões de saúde tenham seus planos de saúde elaborados e monitorados;

- Monitorar e avaliar 100\% dos COAP's implantados;

- Promover a qualificação de $100 \%$ dos Grupos Técnicos das CIRs no âmbito do Estado;

- Garantir a qualificação técnico-administrativa de $100 \%$ dos coordenadores regionais e das secretarias executivas das CIR's no âmbito do Estado;

- Coordenar a elaboração do Contrato Organizativo da Ação Pública de Saúde (COAP) em 100\% das regiões de saúde;

- Apoiar a implantação de 100\% dos COAP's firmados;

- Assessorar e participar na implantação e implementação de pactuações regionais como garantia da oferta de serviços locorregionais, utilizando o espaço das CIR's como fórum de negociação;

- Efetivar o Plano Diretor de Regionalização de forma descentralizada com a participação dos Colegiados Regionais;

- Monitorar e revisar trimestralmente a Programação Pactuada e Integrada PPI;

- Elaborar o Plano Diretor de Investimento - PDI, proporcionando mais autonomia e responsabilização das regiões de saúde do Estado;

- Implantar equipes de apoio integrado com funcionamento regular e instrumentalizando as CIR's para tomada de decisão;

- Estabelecer mecanismo de cooperação e apoio técnico aos municípios no processo de regionalização solidária;

- Apoiar técnico e financeiramente as CIR's, propiciando arranjos institucionais, de forma solidária e cooperativa, reduzindo as desigualdades regionais;" 
- Elaborar instrumentos e indicadores para monitorar o processo de regionalização do SUS;

- Debater o papel do controle social nas CIRs;

- Fortalecimento e construção das redes regionalizadas de atenção em saúde;

- Criar na estrutura organizacional da SES as 09 CIR e os 09 Escritórios Regionais;

- Atualizar o Plano Diretor de Regionalização (PDR) da Saúde nas Comissões Intergestoras Regionais (CIR) com a garantia dos investimentos em Saúde;

- Coordenar, monitorar e avaliar os municípios na elaboração da programação pactuada e integrada (PPI) da atenção à saúde, no âmbito estadual, regional e interestadual;

- Coordenar, monitorar e avaliar anualmente os contratos de gestão interfederativos;

- Ampliação dos serviços assistenciais às macrorregiões de saúde do Estado;

- Realizar avaliação, de base municipal, sobre o acesso da população aos serviços de média e alta complexidade nos municípios, de maneira que venha servir para a revisão da programação da regionalização;

- Promover assinatura de Contratos Organizativos de Ação Pública - COAP com definição de responsabilidades recíprocas em 50\% das Comissões Intergestores Regionais - CIR;

- Elaborar o Mapa da Saúde das 19 regiões da saúde para identificar necessidades de saúde e orientar o planejamento integrado;

- Pactuar a Gestão Compartilhada entre Entes Federativos em 100\% das redes regionais de atenção à saúde implantadas;

- Elaborar 01 Plano Diretor de Investimento para o Estado, contemplando as 19 Regiões de Saúde;

- Fortalecer a gestão regionalizada e descentralizada;

- Fortalecer o planejamento estadual de forma ascendente e participativa;

- Aperfeiçoar o sistema de descentralização e regionalização da assistência farmacêutica;

- Elaborar análise situacional de saúde por região de saúde e redes regionais de atenção à saúde; 
- Elaborar e implementar plano diretor de investimentos (PDRI) para o Estado nas RRAS;

- Estruturar as Redes Regionais de Saúde no Estado;

- Obter $100 \%$ de Municípios com adesão ao Pacto Pela Saúde ou política substitutiva;

- Homologar, na CIB, $100 \%$ das deliberações dos espaços de gestão interfederativa.

\section{Estratégias}

- Qualificação dos processos de elaboração e utilização dos instrumentos de Planejamento do Estado, das regiões e dos municípios;

- Fortalecimento da capacidade de governança regional do SUS.

III) EIXO PLANEJAMENTO REGIONAL

O Eixo Planejamento Regional apresenta a descrição dos resultados encontrados quanto à identificação do planejamento regional pelos Estados, sua realização, responsáveis, metodologias de construção e realização, e propostas ou intenções expressas nos planos estaduais de realiza-lo ou qualifica-lo.

\section{Previsão para Planejamento Regional}

O preenchimento deste indicador foi construído a partir da busca pelas palavras "planejamento regional", "plano regional", "planejamento integrado", "planejamento participativo e regionalizado", "plano integrado", "planejamento regionalizado", e "planejamento integrado e regionalizado". Como resultado da busca foi possível identificar que de todos os 26 planos estaduais analisados apenas 16 deles apresentaram uma ou mais destas palavras. Os Estados são: Acre, 
Alagoas, Amazonas, Bahia, Ceará, Maranhão, Mato Grosso do Sul, Minas Gerais, Pará, Pernambuco, Rio de Janeiro, Rio Grande do Norte, Rio Grande do Sul, Roraima, Sergipe e Tocantins.

Previsão de ações, metas, diretrizes ou objetivos no âmbito do Planejamento Regional

O preenchimento deste indicador levou em consideração a análise das Diretrizes, Objetivos, Ações, Metas e Estratégias expressas nos planos estaduais para o quadriênio 2011 - 2015. Como resultado foram identificados 12 Estados que indicaram alguma ação, meta ou objetivo com esta natureza. Os Estados são: Acre, Alagoas, Amazonas, Bahia, Ceará, Maranhão, Mato Grosso do Sul, Pernambuco, Piauí, Rio Grande do Sul, São Paulo e Sergipe.

\section{O que foi previsto no âmbito do planejamento regional}

A seguir estão descritas as ações, metas, diretrizes e objetivos que foram identificados nos planos estaduais de saúde e que previram elementos no âmbito do Planejamento Regional.

\section{Diretrizes}

- Fortalecimento do planejamento regionalizado e da gestão estratégica do sistema único de saúde no Estado;

- Garantir a política estadual de investimentos em saúde, considerando a conformação das redes de atenção, planos regionais e necessidades da população, visando melhorar a resolutividade e ampliar a cobertura da assistência ambulatorial e hospitalar no Estado;

- Consolidar política de descentralização e fortalecer a regulação;

- Implementação da gestão de acordo com a regulamentação do sus e o desenvolvimento de novos espaços institucionais de planejamento;

- Fortalecer o planejamento estadual de forma ascendente e participativa; 
- Fortalecer a gestão descentralizada do sus;

- Fortalecer o planejamento estadual de forma ascendente e participativa;

- Fortalecer a gestão descentaralizada e regionalizada do SUS;

- Assegurar uma gestão eficiente e efetiva do sistema de saúde, fortalecendo a descentralização, a regionalização e o controle social, com um planejamento integrado e uma Política de gestão do trabalho e da educação permanente em saúde que reforce o compromisso social e ético dos trabalhadores e gestores da saúde.

\section{Objetivos}

- Elaborar um Plano Diretor de Investimentos para o Estado, por região de saúde;

- Apoiar tecnicamente o Planejamento dos municípios e as regiões de saúde na elaboração dos planos de saúde e demais instrumentos de gestão do SUS;

- Implantar a revisão dos mecanismos de Planejamento Regional - PDR, PDI e PPI;

- Aprimoramento do pacto federativo, com o desenvolvimento de processo de contratualização e cooperação entre as esferas e gestão compartilhada do SUS;

- Atualizar e implementar o Plano Diretor de Regionalização do Estado - PDR;

- Elaborar a análise de situação de saúde por região de saúde e redes regionais de atenção à saúde;

- Elaborar e implementar um plano diretor de investimentos para o Estado, na RRAS;

- Estabelecer e implementar as responsabilidades na gestão compartilhada entre os entes federativos do sus.

\section{Ações}

- Redefinir o Plano Diretor de Regionalização; 
- Efetivar Programação Pactuada Integrada (PPI) com repasses coerentes com a realidade da demanda dos serviços de saúde;

- Concluir a Planificação da Atenção Primária na macrorregião de Dourados e realizar o mesmo processo nas macrorregiões de Três Lagoas e Campo Grande;

- Realizar o planejamento integrado da saúde;

- Elaborar o Mapa da Saúde das 19 regiões da saúde para identificar necessidades de saúde e orientar o planejamento integrado;

- Pactuar a Gestão Compartilhada entre Entes Federativos em 100\% das redes regionais de atenção à saúde implantadas;

- Promover assinatura de Contratos Organizativos de Ação Pública - COAP com definição de responsabilidades recíprocas em $50 \%$ das Comissões Intergestores Regionais - CIR;

- Elaborar 01 Plano Diretor de Investimento para o Estado, contemplando as 19 Regiões de Saúde.

\section{Metas}

- Fortalecer as instâncias colegiadas no SUS (CIB, CES e CIRs);

- Implantar "sala de situação" na SES, com extensão para as Comissões Intergestores Regionais (CIRs) e para 50\% dos municípios do Estado;

- Elaborar em parceria com a CIR 10 mapas e 10 planos regionais de saúde;

- Realizar o planejamento integrado da saúde, envolvendo 100\% das regionais, conforme pactuação relativa ao COAP;

- Realizar Avaliação de 100 \% dos COAPs;

- Pactuar a gestão compartilhada entre os entes federativos em $100 \%$ das RRAS; 


\section{Responsáveis pelo Planejamento Regional}

Os responsáveis pelo planejamento regional foram identificados e descritos em 6 planos estaduais: Ceará, Pará, Rio Grande do Sul, Acre, Amazonas e Pernambuco. Vale ressaltar que $O$ Estado do Paraná foi retirado da amostra, uma vez que pela análise identificou-se que o Estado não apresenta planejamento regional, só apresenta responsáveis.

O Estado de Ceará já firmou compromissos com o COAP em 2011 e vem apresentado uma forma de planejamento integrado e regionalizado. O resultado é uma agenda estratégica estadual produzida a partir do planejamento realizado nas regiões de saúde no Estado, considerando as diretrizes, ações e metas prioritárias para o desenvolvimento de cada região. De acordo com o plano estadual são realizadas oficinas regionais coordenadas pela Vice-Governadoria e pela Secretaria de Planejamento e Gestão do Estado com condução mediada pela equipe técnica de planejamento da Secretaria de Saúde - SESA.

Quanto ao Estado do Pará, é o Núcleo de Informação e Planejamento em Saúde da SESPA quem tem a responsabilidade de Construção, monitoramento e avaliação dos Instrumentos do Planejamento da Saúde, no âmbito Estadual, e capacitação e assessoramento aos Centros Regionais de Saúde e complementativamente aos municípios para o processo de elaboração desses instrumentos. Por consequência o núcleo de informação e Planejamento da SESPA realizou o planejamento regional do Pará entre os anos de 2010 e 2011.

No Rio Grande do Sul o gestor estadual é responsável pela coordenação e pelo desenvolvimento de estratégias de planejamento, monitoramento e de avaliação do Sistema Único de Saúde. Em nível organizacional/administrativo da Secretaria da Saúde do Estado existem grupos de trabalho que foram organizados para construir uma discussão integrada sobre os processos de planejamento, monitoramento e de avaliação da gestão. Esses grupos são denominados de Grupos de Trabalho de Planejamento, Monitoramento e Avaliação. Existe um GT em nível central da SES (GT PMA da Gestão) e dezenove GTs Regionais, sendo um em cada Coordenadoria de Saúde. 
O texto base do plano estadual do Estado do Acre não apresentou responsáveis pelo planejamento regional em seu território, apenas apresentou propostas e registrou a intenção de proporcionar apoio técnico da secretaria estadual na elaboração e condução dos planos municipais e regionais.

A Secretaria de Saúde do Estado do Amazonas (SUSAM) estabeleceu parceria com o Conselho Nacional de Secretários Estaduais de Saúde (CONASS) visando instrumentalizar o processo de planejamento regional da saúde e apoiar os municípios na organização e funcionamento das RAS a partir da Atenção Primária em Saúde (APS). Este apoio proporcionou a realização de oficinas voltadas a capacitação de facilitadores que atuaram nas regionais de saúde, considerando o novo modelo de RAS estabelecendo a APS como ordenadora e coordenadora desse processo, iniciando a capacitação pela Regional do Médio Amazonas com a participação de seis municípios.

No Estado de Pernambuco, as Gerências Regionais de Saúde - GERES são as unidades técnicoadministrativas da Secretaria Estadual de Saúde que têm a missão de planejamento, execução, acompanhamento, monitoramento e avaliação das ações/serviços de saúde e das diretrizes da política estadual de saúde em cada Região de Saúde.

\section{Realização e construção do Planejamento Regional}

Foram identificados apenas 5 Estados que em seu texto base descreveram como o planejamento regional foi realizado. São eles os Estados do Ceará, Tocantins, Pará, Rio Grande do Norte e Rio Grande do Sul.

No Ceará o planejamento regional foi fruto de 17 oficinas regionais que geraram ações para a região de saúde. É importante ressaltar que as oficinas regionais ocorreram antes da elaboração do plano estadual e o resultado destas 17 oficinas tornou-se o plano estadual. O plano é bem curto e simples, causa estranheza a quem está acostumando com os planos que não realizam planejamento regional. Foi observado ainda que nas oficinas regionais foram levantados vários objetivos em comum, e outros inovadores. 
Em Tocantins foram realizadas diversas reuniões entre os representantes dos municípios, os antigos CGR's, e com as superintendências de Vigilância e Proteção à Saúde; Gestão Administrativa e de Desenvolvimento dos Recursos Humanos e Atenção e Promoção a Saúde do Estado. A partir destes encontros foram discutidas e pactuadas as agendas da gestão e governança regional, que incluem o planejamento regional. No entanto, o plano se refere à construção dos PDR e PDRI como o planejamento regional, apesar de também ter realizado o levantamento dos problemas de saúde e de gestão de cada região de saúde para a construção do plano estadual.

No Estado do Pará foram realizadas nove oficinas, com um total de 376 participantes, no período de 2010 a 2011, proporcionando um espaço de discussão, para a construção de um Planejamento Regional, com a participação de Diretores de Centros Regionais de Saúde, Secretários Municipais de Saúde, Conselhos Gestores Regionais, Colegiado de Secretários Municipais de Saúde - COSEMS e Conselho Estadual de Saúde - CES, a partir de uma análise situacional dos municípios, visando traçar metas, por meio de estratégias que atendam às demandas da população, de acordo com suas particularidades em relação ao perfil epidemiológico, acesso, integralidade e à qualidade dos serviços oferecidos, cujo resultado desse processo foi o Plano Diretor de Regionalização e Investimentos (PDRI).

O plano estadual do Rio Grande do Norte não declara uma metodologia de planejamento regional, mas apresenta um modelo de planejamento que expressa grande participação regional a partir das CIB, CIR e dos conselhos de saúde. $O$ plano expressa ainda:

\footnotetext{
...espera-se que este instrumento de gestão (plano estadual) possa impulsionar e respaldar o funcionamento do sistema de forma efetiva, direcionando a programação e a operacionalização de ações articuladas, intra e inter-institucionalmente, capazes de garantir aos cidadãos o seu direito à saúde, tornando-se um referencial para a elaboração do planejamento regional e dos planos municipais de saúde, bem como para a conformação das redes temáticas de saúde, possibilitando o atendimento das demandas de saúde da população do RN de forma equânime, integral e solidária.
}

A partir desta colocação, fica entendido que a organização e execução de um plano regional está mais voltado para um planejamento integrado entre as considerações das CIB e CIR que deverão estar envolvidas neste processo. No 
entanto, a proposição de que é a partir do plano estadual que serão norteadas as formulações dos planos regionais e municipais vai na contramão das proposições do planejamento ascendente.

No Estado do Rio Grande do Sul foram organizados GT's de Planejamento, Monitoramento e Avaliação da Gestão da Secretaria de Saúde, e Coordenadorias Regionais de Saúde (CRS). As CRS são responsáveis por discutir a organização territorial e regional a fim de proporcionar a governança regional no Estado e construção de planejamento regional. No entanto, os responsáveis pelo planejamento regional e sua pactuação são as CIR's.

No plano estadual do RS todos os indicadores foram apresentados na base regional apresentando as desigualdades e fragilidades regionais no Estado. Esta conformação permitirá que os planos regionais sejam realizados, assim como viabilizar a elaboração do COAP no Estado.

Em síntese, observa-se que muitos Estados consideram apenas a construção do PDR como a realização de um planejamento regional, o que de fato não poderia representar um plano regional, uma vez que o PDR apenas expressa a conformação das regiões de saúde de um Estado, mas não ordena ou programa as ações e serviços de saúde de acordo com as dificuldades ou especificidades de cada região. O PDI provavelmente tem uma característica de plano regional muito mais expressiva que o próprio PDR, uma vez que ele apresenta uma programação de investimentos regionais considerando as necessidades regionais. Há de se considerar então que talvez a construção dos PDRI's de forma compartilhada e completa possa até ser entendida como a construção de um planejamento regional, mas não simplesmente a construção dos PDR. 
IV) EIXO PLANEJAMENTO

\section{Previsão de fortalecimento do PPI}

Quatorze planos estaduais preveem o fortalecimento ou aprimoramento da Programação Pactuada e Integrada (PPI). Dentre as ações encontradas para o seu fortalecimento e aprimoramento estão:

- Efetivar a PPI com repasses coerentes com a realidade da demanda dos serviços de saúde;

- Fornecer apoio técnico às repactuações da PPI intermunicipais;

- Realizar anualmente $100 \%$ das demandas de repactuação, revisão e operacionalização da Programação Pactuada e Integrada da Assistência entre o Estado e Municípios;

- Elaborar, acompanhar e avaliar a PPI de acordo com as necessidades da população dos municípios;

- Implantar a revisão dos instrumentos de Planejamento Regional - PDR, PDI e PPI;

- Implantar a revisão de um instrumento de planejamento regional - PPI;

- Implantar a PPI interestadual da Rede Pernambuco-Bahia (PEBA);

- Coordenar, monitorar e avaliar os municípios na elaboração da PPI da atenção à saúde, no âmbito estadual, regional e interestadual;

- Subsidiar o processo da PPI e sua sucedânea - a Programação Geral de Ações e Serviços de Saúde - PGASS;

- Incorporar a PPI e o PDR no processo regulatório, disponibilizando informações sobre as referências entre municípios;

- Ampliar de 87,24\% para 90\% o cumprimento dos Procedimentos de Média e Alta Complexidade da PPI estadual;

- Estruturar os processos de regulação e contratualização de serviços para garantir o cumprimento da PPI; 
- Aperfeiçoar a PPI da assistência como instrumento organizador do acesso nas regiões de saúde;

- Revisar a PPI;

- Revisar, Atualizar, Executar e Monitorar regularmente a PPI da Assistência à Saúde - PPI/AS;

- Cumprir a PPI da Assistência por meio dos processos de regulação e contratualização dos serviços;

- Aperfeiçoar a Programação Pactuada e Integrada da assistência como instrumento organizador do acesso, nas regiões de saúde e nas linhas de atenção prioritárias;

- Desenvolver, a partir da identificação das necessidades, um processo de planejamento, regulação, programação pactuada e integrada da atenção à saúde, monitoramento e avaliação;

- Organizar e pactuar com os municípios, o processo de referência intermunicipal das ações e serviços de média e alta complexidade a partir da atenção básica, de acordo com a programação pactuada e integrada da atenção à saúde.

\section{Construção do Plano Estadual}

O quadro a seguir apresenta a síntese das metodologias utilizadas em cada Estado brasileiro para subsidiar a construção do Plano Estadual de Saúde. A análise buscou identificar as metodologias de planejamento utilizadas com ênfase na identificação da relevância que as regiões de saúde possuíram neste processo.

Para a construção do quadro abaixo foram consideradas apenas as informações fornecidas pelos planos estaduais. Aqueles planos que não apresentaram informações definindo como o planejamento estadual foi realizado não foram considerados para esta análise. 
Quadro 01 - Síntese da metodologia de construção do plano estadual de saúde dos Estados brasileiros 2011 - 2015.

\begin{tabular}{|c|c|}
\hline ESTADO & SINTESE \\
\hline Ceará & $\begin{array}{l}\text { Construção de um processo de planejamento participativo e } \\
\text { regionalizado a partir da indução de } 17 \text { oficinas regionais } \\
\text { sob condução da equipe de planejamento da SES. }\end{array}$ \\
\hline $\begin{array}{l}\text { Mato Grosso } \\
\text { do Sul }\end{array}$ & $\begin{array}{l}\text { O processo de planejamento estadual contou com um } \\
\text { diagnóstico situacional das } 11 \text { regiões de saúde do Estado } \\
\text { que foi realizado por uma equipe da SES que se instalou } \\
\text { por uma semana em cada região. Este relatório foi discutido } \\
\text { pelos gestores regionais da CIR e CIB assim como validado } \\
\text { pelo Conselho Estadual de saúde. }\end{array}$ \\
\hline $\begin{array}{l}\text { Minas } \\
\text { Gerais }\end{array}$ & $\begin{array}{l}\text { Foram realizadas } 19 \text { reuniões entre a Secretaria de Estado } \\
\text { de Saúde e o Conselho Estadual de Saúde, com a } \\
\text { finalidade de discutir as diretrizes, as respostas sociais, as } \\
\text { metas e o público-alvo abordados no Plano Estadual de } \\
\text { Saúde. Essas reuniões foram o meio encontrado para a } \\
\text { concretização do Plano, de forma democrática e deliberada, } \\
\text { através da construção social entre SES, CES, vinculadas e } \\
\text { órgãos do Estado. }\end{array}$ \\
\hline Paraná & $\begin{array}{l}\text { O plano foi desenvolvido pela SES e discutido com o } \\
\text { Conselho de Saúde. }\end{array}$ \\
\hline Pará & $\begin{array}{l}\text { Realização de } 9 \text { oficinas pela SES com objetivo de realizar } \\
\text { planejamento regional contando com a participação de } \\
\text { Diretores de Centros Regionais de Saúde, Secretários de } \\
\text { Saúde, Conselhos gestores Regionais, Colegiados de } \\
\text { secretários municipais de saúde - COSEMS e Conselho } \\
\text { estadual de saúde - CES. O resultado deste processo foi o } \\
\text { PDRI. }\end{array}$ \\
\hline & $\begin{array}{l}\text { O Planejamento Estadual foi realizado conforme definido } \\
\text { pelo PlanejaSUS e seguiu a metodologia do PES. }\end{array}$ \\
\hline $\begin{array}{l}\text { Rio Grande } \\
\text { do Sul }\end{array}$ & $\begin{array}{l}\text { Teve como orientador o Decreto Presidencial no } 7.508 / 2011 \\
\text { e como subsídios o desenho do Mapa Estratégico do } \\
\text { Governo, o Plano Plurianual Participativo } 2012-2015 \text { e a } \\
\text { definição do novo desenho das Regiões de Saúde, os quais } \\
\text { forneceram as bases para a composição do instrumento. } \\
\text { Contou com a construção do COSEMS. Tal processo, que } \\
\text { visa à indução do planejamento regional, buscou garantir a } \\
\text { participação dos municípios, tendo em vista a futura } \\
\text { concretização do Contrato Organizativo da Ação Pública } \\
\text { (COAP), que deverá ser discutido no âmbito das Comissões } \\
\text { Intergestores Regionais - CIR, firmado em cada uma das } \\
\text { trinta regiões de saúde. }\end{array}$ \\
\hline
\end{tabular}




\begin{tabular}{|c|c|}
\hline Acre & $\begin{array}{l}\text { O processo de planejamento estadual buscou ser } \\
\text { ascendente e participativo. Foram realizadas oficinas com } \\
\text { representantes da Secretaria Estadual de Saúde, das } \\
\text { Secretarias Municipais de Saúde, das Comissões } \\
\text { Intergestores Regionais - CIR, dos prefeitos, das Câmaras } \\
\text { Municipais e de conselheiros de saúde. Foram realizadas } \\
22 \text { oficinas nos municípios do Estado e nas } 03 \text { regionais. }\end{array}$ \\
\hline Alagoas & $\begin{array}{l}\text { O plano estadual afirma ter sido construído de forma } \\
\text { ascendente e participativa mas não apresenta a } \\
\text { metodologia utilizada ou os atores envolvidos. O plano } \\
\text { afirma ainda ter se alicerçado na política de planejamento } \\
\text { do SUS respeitando as propostas da Conferência de saúde, } \\
\text { os compromissos do Estado e do governo federal. }\end{array}$ \\
\hline Amazonas & $\begin{array}{l}\text { O planejamento Estadual foi desenvolvido com a mesma } \\
\text { estrutura dos planos estaduais comuns, com análise de } \\
\text { situação e objetivos, diretrizes e metas. O plano foi } \\
\text { desenvolvido entre os técnicos da Secretaria de Saúde, das } \\
\text { Fundações de Saúde e do controle social. }\end{array}$ \\
\hline Pernambuco & $\begin{array}{l}\text { O plano estadual foi construído pela Diretoria Geral de } \\
\text { Planejamento da SES e afirma ter sido construído de forma } \\
\text { participativa, no entanto o planejamento foi construído } \\
\text { consultado o colegiado dos secretários executivos, gestores } \\
\text { municipais, Conselho de Saúde e o Governo do Estado. } \\
\text { Seu encaminhamento final foi dado mediante aprovação } \\
\text { pela Conferência Estadual de Saúde. }\end{array}$ \\
\hline Amapá & $\begin{array}{l}\text { A elaboração do plano estadual foi realizada pelos gestores } \\
\text { municipais de saúde e do conselho de saúde do Estado. A } \\
\text { agenda foi construída ainda considerando os objetivos do } \\
\text { governo estadual. }\end{array}$ \\
\hline Bahia & $\begin{array}{l}\text { O Estado da Bahia desenvolveu seu plano estadual de } \\
\text { saúde a partir das definições consolidadas pela SEPLAN } \\
\text { para compor o plano de desenvolvimento do Estado até o } \\
\text { ano de } 2023 \text {. Contou também com a elaboração do projeto } \\
\text { político de governo para os anos de } 2011 \text { a } 2014 \text { que } \\
\text { estabeleceu diretrizes para a saúde. A partir destes } \\
\text { documentos foi desenvolvido o programa Bahia Saudável, } \\
\text { elaborado em parceria com o Instituto de Saúde Coletiva da } \\
\text { Universidade Federal da Bahia. O programa Bahia } \\
\text { Saudável consolidou-se como programa de governo após } \\
\text { ser subsidiado com as discussões realizadas durante a } \\
\text { construção do PPA e da LOA. A análise de situação do } \\
\text { plano foi desenvolvida pala Secretaria de saúde em parceria } \\
\text { com a OPAS e as propostas das conferências municipais de } \\
\text { saúde foram consideradas na formulação do plano. O } \\
\text { Programa Bahia Saudável também foi pauta das discussões } \\
\text { entre os colegiados ampliados da SESAB, e por fim } \\
\text { discutido entre as áreas da secretaria para finalização do do }\end{array}$ \\
\hline
\end{tabular}




\begin{tabular}{|c|c|}
\hline & documento PES 2012 - 2015. \\
\hline Goiás & $\begin{array}{l}\text { A construção do plano contou com a participação do } \\
\text { Conselho Nacional de Secretários de Saúde (CONASS), } \\
\text { Conselho Estadual de Saúde (CES), das Universidades, do } \\
\text { Conselho dos Secretários Municipais de Saúde (COSEMS) } \\
\text { e dos representantes de áreas estratégicas da Secretaria } \\
\text { Estadual de Saúde de Goiás (SES-GO), da Secretaria } \\
\text { Executiva da Comissão Intergestores Bipartite (CIB), entre } \\
\text { outros. Na elaboração, procurou-se compatibilizá-lo com o } \\
\text { Plano de Governo, o Plano Plurianual (PPA) e o Plano de } \\
\text { Ação Integrada de Desenvolvimento (PAI), na perspectiva } \\
\text { de integração entre o planejamento e orçamento estadual e } \\
\text { com as recomendações da } 7^{\text {a }} \text { Conferência Estadual de } \\
\text { Saúde. }\end{array}$ \\
\hline Maranhão & $\begin{array}{l}\text { A construção do plano estadual foi coordenada pela } \\
\text { Assessoria de Planejamento e Ações Estratégicas da SES } \\
\text { que contou com a participação das demais assessorias da } \\
\text { secretaria de saúde do Estado. Foram realizados } \\
\text { seminários regionais de lideranças em } 11 \text { localidades para } \\
\text { debater as dificuldades encontradas nas regiões de saúde } \\
\text { assim como suas demandas. Utilização da metodologia da } \\
\text { arvore de problemas para o levantamento das dificuldades. } \\
\text { Aproveitamento das diretrizes da conferência de saúde } \\
\text { estadual no plano e da } 14 \text { CNS, avaliação do PPA anterior, } \\
\text { e oficina de trabalho para desenvolver as redes de atenção } \\
\text { com a CIR. }\end{array}$ \\
\hline Paraíba & $\begin{array}{l}\text { A elaboração deste Plano partiu de uma análise sobre a } \\
\text { situação de saúde do Estado da Paraíba, com a } \\
\text { subsequente seleção e priorização dos principais } \\
\text { problemas, de maneira a subsidiar o planejamento, } \\
\text { operacionalização, monitoramento e avaliação das ações de } \\
\text { saúde, considerando todas as necessidades de saúde para } \\
\text { cada uma das regiões do Estado. }\end{array}$ \\
\hline Piauí & $\begin{array}{l}\text { A construção do plano tem seu início a partir da publicação } \\
\text { do PPA do Estado, seguiu pautando as prioridades do } \\
\text { ministério da saúde, dos municípios do Estado e por último } \\
\text { das diretrizes da conferência estadual de saúde. }\end{array}$ \\
\hline $\begin{array}{c}\text { Santa } \\
\text { Catarina }\end{array}$ & $\begin{array}{l}\text { O plano estadual foi construído utilizando a metodologia do } \\
\text { PES. Contou com a participação de trabalhadores do SUS, } \\
\text { de gestores e do controle social sendo realizadas oficinas } \\
\text { para discutir a análise de situação do Estado e das demais } \\
\text { etapas do plano. De acordo com a agenda estratégica o } \\
\text { plano foi construído de forma participativa. }\end{array}$ \\
\hline
\end{tabular}




\begin{tabular}{|l|l|}
\hline \multirow{5}{*}{ São Paulo } & $\begin{array}{l}\text { Foi construída uma versão preliminar do plano que contou } \\
\text { com a participação das áreas da SES. Esta versão foi } \\
\text { encaminhada para discussão em uma oficina bipartite que } \\
\text { contou com coordenadores e técnicos de nível regional } \\
\text { (CGR e DRS). Ainda nesta oficina foi apresentado o } \\
\text { diagnóstico situacional do Estado e discutido à luz do } \\
\text { decreto 7.508. A versão preliminar foi discutida pelos } \\
\text { departamentos regionais de saúde e pelo conselho, que } \\
\text { realizou mais cinco oficinas regionais até a validação final } \\
\text { do plano. O plano foi validado e aprovado pelo conselho. }\end{array}$ \\
\hline
\end{tabular}




\section{QUANDRO 02 - Síntese de resultados de análise}

\begin{tabular}{|c|c|c|c|c|c|c|c|c|c|c|c|c|c|c|c|c|c|c|c|c|c|c|c|c|c|c|c|}
\hline \multirow{2}{*}{ CATEGORIAS } & \multicolumn{26}{|c|}{ ESTADOS } & \multirow{2}{*}{ TOTAL } \\
\hline & AC & AL & AP & AM & BA & CE & ES & Go & MA & MT & MS & MG & PA & PB & PR & PE & $\mathbf{P I}$ & RJ & RN & RS & RO & $\mathbf{R R}$ & sc & SP & SE & то & \\
\hline \multicolumn{28}{|c|}{ EIXO REGIONALIZAÇÃO } \\
\hline $\begin{array}{c}\text { Previsão de metas } p / \\
\text { região }\end{array}$ & $\mathrm{x}$ & $x$ & $\mathrm{x}$ & $x$ & $\mathrm{x}$ & $x$ & $x$ & $x$ & $x$ & $x$ & $\mathrm{x}$ & $\mathrm{x}$ & & $x$ & $x$ & $x$ & $x$ & $x$ & $x$ & $\mathrm{x}$ & $x$ & $\mathrm{NI}$ & $x$ & $x$ & $x$ & $x$ & 24 \\
\hline Fortalecimento da CIR & $x$ & & & $x$ & & & & $\mathrm{x}$ & & $x$ & & $x$ & $\mathrm{NI}$ & $\mathrm{x}$ & $\mathrm{NI}$ & $\mathrm{x}$ & $\mathrm{x}$ & $x$ & $\mathrm{x}$ & $\mathrm{x}$ & $\mathrm{x}$ & $\mathrm{NI}$ & $x$ & & $x$ & $x$ & 15 \\
\hline Assinatura do COAP & & $\mathrm{x}$ & & $x$ & & $x$ & $x$ & $x$ & $x$ & $x$ & $x$ & $x$ & & $x$ & $\mathrm{x}$ & $\mathrm{x}$ & $x$ & $x$ & $x$ & & & $\mathrm{NI}$ & & & $x$ & $\mathrm{x}$ & 17 \\
\hline Utilização do PDR & $\mathrm{x}$ & $x$ & $x$ & & $x$ & $x$ & $x$ & $x$ & & & $x$ & & $x$ & $x$ & $x$ & & $x$ & $x$ & $x$ & $x$ & & & & $x$ & $x$ & $x$ & 18 \\
\hline Componente regional & & $\mathrm{x}$ & $x$ & & $x$ & $\mathrm{x}$ & $\mathrm{x}$ & & $\mathrm{x}$ & $\mathrm{x}$ & & $x$ & $x$ & $\mathrm{x}$ & $x$ & $\mathrm{x}$ & & & $\mathrm{x}$ & $\mathrm{x}$ & & $\mathrm{x}$ & $x$ & & $\mathrm{NI}$ & $x$ & 17 \\
\hline $\begin{array}{c}\text { Indicadores base } \\
\text { regional }\end{array}$ & & $x$ & & & $x$ & $x$ & & & $x$ & & & $x$ & $x$ & & $x$ & $x$ & $x$ & $x$ & $x$ & $x$ & & $x$ & $x$ & $x$ & & $x$ & 16 \\
\hline \multicolumn{28}{|c|}{ EIXO PLANEJAMENTO REGIONAL } \\
\hline Citou PR & $x$ & $\mathrm{x}$ & & $x$ & $\mathrm{x}$ & $\mathrm{x}$ & & & $\mathrm{x}$ & & $x$ & $\mathrm{x}$ & $x$ & & & $\mathrm{x}$ & & $x$ & $x$ & $x$ & & $x$ & & & $x$ & $\mathrm{x}$ & 16 \\
\hline $\begin{array}{c}\begin{array}{c}\text { Possui ações, dir, obj, } \\
\text { metas para o PR }\end{array} \\
\end{array}$ & $x$ & $x$ & & $x$ & $x$ & $x$ & & & $x$ & & $x$ & & & & & $x$ & $x$ & & & $x$ & & $\mathrm{NI}$ & & $x$ & $x$ & & 12 \\
\hline $\begin{array}{c}\text { Apresenta responsáveis } \\
\text { pelo PR } \\
\end{array}$ & $\mathrm{x}$ & & & $x$ & & $x$ & & & & & & & $x$ & & & $x$ & & & & $x$ & & & & & & & 6 \\
\hline Construção do PR & & & & & & $x$ & & & & & & & $x$ & & & & & & $\mathrm{x}$ & $x$ & & & & & & $\mathrm{x}$ & 5 \\
\hline \multicolumn{28}{|c|}{ EIXO PLANEJAMENTO ESTADUAL } \\
\hline Fortalecimento da PPI & & $x$ & $x$ & & $x$ & $x$ & $x$ & & & $\mathrm{x}$ & & $x$ & & & & $\mathrm{x}$ & $x$ & & $x$ & & $x$ & $\mathrm{NI}$ & $\mathrm{x}$ & $x$ & & $x$ & 14 \\
\hline
\end{tabular}




\section{DISCUSSÃO}

Este estudo buscou identificar as características do processo de planejamento integrado e regionalizado nos Estados brasileiros. Com este objetivo, a metodologia do estudo proporcionou com que os resultados encontrados fossem descritos por eixos de análise. Cada um destes eixos foram desenvolvidos para identificar aspectos relevantes ao estudo do processo de planejamento integrado e regionalizado no país, o que significou inicialmente descrever as características de cada Estado, como sua população e quantidade de regiões de saúde.

Na primeira categoria de análise foi levado em conta também a quantidade de planos de saúde que apresentam em seu texto as palavras planejamento regional ou planejamento integrado. Em apenas 16 planos de saúde foram encontradas estas palavras, o que significa que em ao menos 10 planos estaduais a discussão sobre o planejamento integrado e regionalizado nem ao menos foi levantada.

Este resultado pode estar associado à desqualificação da agenda estratégica do Estado e seu plano de saúde, indicando um descompromisso com as políticas e estratégias de planejamento integrado e regionalizado e até mesmo ao processo de regionalização nos Estados.

Vale ressaltar, neste contexto, a importância do Plano de Saúde, que foi regulamentado pelo artigo 36 da Lei № 8.080 de 1990 - dita Lei Orgânica da Saúde como instrumento básico de planejamento setorial, cabendo aos Conselhos de Saúde formular diretrizes para sua elaboração e aprovação, a fim de que os recursos da esfera federal destinados as ações e serviços de saúde sejam repassados aos Estados (BRASIL, 1990).

Ainda de acordo com a Lei Orgânica da Saúde, em seu $\S 2^{\circ}$, determina-se que será vedada a transferência de recursos para o financiamento de ações não previstas nos planos de saúde. Esta determinação fundamenta ainda mais a relevância dos planos de saúde como instrumento de governo, cabendo aos gestores construir com sabedoria os planos de saúde (BRASIL, 1990). 
É nesse sentido que se reforça a ideia de que a não inclusão da construção de processos de planejamento regional, ou fortalecimento e incorporação dos instrumentos de regionalização e planejamento integrado na agenda estratégica dos planos de saúde, representa a desqualificação ou descompromisso da gestão estadual para com o processo de planejamento integrado e regionalizado da saúde.

Quanto aos demais achados do primeiro eixo de análise, é importante ressaltar que não houve associação entre a presença do planejamento integrado ou regionalizado e o contingente populacional dos Estados e o número de regiões de saúde. Quanto a esse fator, indica-se o levantamento de outras possíveis variáveis que podem explicar a divergência entre os Estados, tais como: existência e atuação das CIR's, controle social atuante e participante das instâncias regionais ou até mesmos o advento de mecanismos formais de regionalização, como o COAP. Para a elucidação dessas possibilidades, sugere-se novos estudos nesses caminhos.

Por outro lado, observa-se que a maioria dos Estados de maior população mencionaram o planejamento regional, apesar deste achado não ter sido preponderante para a diferença entre os grupos. Ressalta-se, ainda, a inclusão do Estado de São Paulo, que mesmo não tendo mencionado a realização do planejamento regional em seu plano de saúde apresentou grande participação das regiões de saúde e das instâncias regionais na elaboração do seu plano estadual.

O segundo eixo de análise identificou aspectos referentes ao processo de regionalização nos Estados. Esta análise tornou-se tão importante quanto o estudo do planejamento regional propriamente dito, uma vez que a consolidação das políticas de descentralização e regionalização da saúde nos Estados brasileiros devem ser ordenadoras do processo de planejamento integrado. Afinal, como seria possível analisar um processo de planejamento integrado entre entes federados e regiões de saúde sem identificar as devidas conformações regionais estabelecidas pelos Estados?

Os resultados iniciais do segundo eixo apontaram que praticamente todos os Estados apresentaram metas para a região de saúde. Resultado este que se contrapõe ao encontrado na categoria que identifica em quais bases os indicadores da análise de situação estão dispostos, se estaduais, regionais ou municipais. Observa-se que, mesmo tendo muitos planos que não organizam suas análises de 
situação considerando as bases regionais, praticamente todos os planos propõem metas para as regiões de saúde na agenda estratégica.

Outra observação importante está na alta frequência com que aparecem metas regionais voltadas para a construção das RRAS. Em sua maioria, as metas regionais estão voltadas para a consolidação da oferta de serviços nas regiões de saúde, no entanto, a análise de situação na maioria dos planos não se atem em construir indicadores regionais para identificar as condições de saúde da população da região. Então, como fortalecer o processo de regionalização nos Estados se a região está voltada apenas para o provimento da oferta de serviços?

Esta observação nos leva a identificar que os Estados brasileiros estão buscando, mesmo que de maneira ainda inconsistente, organizar a oferta de seus serviços de saúde a partir de redes regionalizadas. No entanto, a demanda ou oferta de serviços de saúde não está sendo dimensionada a partir das necessidades regionais. Esta é uma observação apontada, inclusive, por diversos planos de saúde que também reconheceram os serviços de saúde sendo planejados a partir da oferta, e não da demanda e real necessidade da população.

Quanto ao fortalecimento das CIR's, observa-se que as ações, metas ou diretrizes previstas com este objetivo foram previstas em apenas 15 planos e estão voltadas com maior frequência para o reconhecimento, ampliação, fortalecimento e qualificação das CIR's. Estas considerações apontam para o reconhecimento de uma estrutura ainda em desenvolvimento, que está em formação ou consolidação.

Em síntese, observa-se que a construção e fortalecimento das CIR's ainda não é unanimidade nos planos de saúde, levando em conta que apenas um pouco mais da metade dos planos de saúde previram ações para o fortalecimento ou reconhecimento da CIR's. Entretanto, apesar das CIR's terem sido estabelecidas pelo Decreto 7.508 (BRASIL, 2011), instituído em 2011, todos os planos analisados neste estudo foram desenvolvidos entre os anos de 2011 e 2012. Significa que no momento em que estes planos estavam em construção, o marco normativo que institui as CIR's estava sendo implementado. Neste contexto, entende-se que os planos de saúde, em sua totalidade, deveriam prever em suas agendas a construção, ampliação, ou, no mínimo, a implementação das CIR's nas regiões. 
A mesma análise se faz quanto à assinatura do COAP, que encontramos na maioria dos planos de saúde a intenção de assina-lo, implementa-lo ou de proporcionar sua adesão. No entanto, o que se observa em 2016 - após o termino da vigência dos planos analisados 2012 a 2015 - é que mesmo tendo sido objetivo firmado nos planos de saúde estaduais, a assinatura do COAP só se consolidou em dois Estados brasileiros: Mato Grosso do Sul e Ceará.

Assim como as CRI's, o COAP foi estabelecido em 2011 pelo decreto 7.508, o que significa que também esteve em alta a sua discussão durante a elaboração dos planos estaduais de saúde. Entretanto, mesmo sendo sua assinatura bastante pleiteada pelos planos estaduais de saúde, o COAP obteve baixíssima adesão até o ano de 2016.

A baixa adesão ao COAP pelos entes federados pode ser explicada por diversos fatores e dificuldades já levantados em outros estudos. Uma das importantes dificuldades que podemos apontar, é o receio que os gestores possuem em se comprometer formalmente, por meio de contrato, com a gestão solidária entre si e os municípios vizinhos que compõe sua região de saúde (SANTOS e CAMPOS, 2015). Esta discussão é abordada também pelo professor Gastão Wagner de Sousa Campos, que aponta como razão para a dificuldade da regionalização a característica paternalista, patrimonialista e clientelista do poder no Estado brasileiro, exercido pelos gestores nas três esferas de gestão (CAMPOS, 2015).

Além das dificuldades para a adesão ao COAP, outro fator que chama atenção nesta análise é o alto número de Estados que apresentam em seus planos o objetivo de assinar o COAP, e que ao final da vigência dos planos, não o fizeram. Nesta perspectiva, levanta-se ainda o questionamento da seriedade com que os gestores encaram os compromissos firmados nos planos de saúde. Seriam os planos de saúde apenas meras peças formais estipuladas por lei, mas que seus objetivos não são buscados de forma seria pelos gestores? Ou o contexto não favoreceu?

Em uma de suas três advertências, Carlos Matus afirma que "devemos entender a planificação como uma dinâmica de cálculo que precede e preside a ação, que não cessa nunca, sendo processo contínuo, que acompanha a realidade mutável" (MATUS, 1987). Neste caso, o processo de planejamento não pode ser 
encarado apenas como o plano, ou o documento fruto deste processo, tendo em vista que os cenários e realidades que configuram o mundo real sofrem alterações (CARDOSO, 2013).

Portanto, o documento plano torna-se apenas uma peça de vida efêmera, sendo assim o processo de planejamento em si, uma cultura que deve ser constante e permanente. Por sua vez, o plano, ou livro-plano, também possui sua importância, devendo existir para que sejam documentados e firmados os acordos estabelecidos. Sendo assim, o plano apresenta os caminhos para onde se deseja seguir, é a expressão dos caminhos a serem seguidos para alcançar a visão de futuro (CARDOSO, 2013).

Para que o processo de planejamento seja constante e vivo, é preciso que haja monitoramento e avaliação constante das metas, sendo permanentemente revisado para se manter atual. Este resultado pode ser configurado como uma evidência da necessidade de realização do planejamento integrado e regionalizado. Uma vez que os planos forem elaborados e revisados permanentemente entre municípios, regiões e os Estados, será possível construir agendas com maior comprometimento entre sua realização (TANCREDI et al, 1998).

A terceira análise realizada neste estudo identificou os aspectos e conformações do processo de planejamento integrado e regionalizado desenvolvido pelos Estados. Neste momento, pôde-se identificar quais Estados brasileiros realizaram o planejamento integrado e regionalizado, a relevância que o processo de planejamento integrado possui nos planos estaduais de saúde, e até mesmo o que alguns Estados entendem por planejamento regional.

A princípio, observa-se que em 16 planos estaduais de saúde se encontram alguma das palavras chave para a identificação do planejamento regional. No entanto, em apenas 12 destes planos foram identificadas diretrizes, objetivos, ações ou metas que se referiram ao planejamento regional apontando melhorias ou encaminhamentos com esta temática.

regional, como "Planejamento Participativo e Regionalizado", "Planejamento Regional da Atenção Básica", "Planejamento Integrado da Saúde" e o propriamente dito "Planejamento Regional". 
Durante a análise, foi identificado apenas um descritor - demonstrado pelo Estado do Rio Grande do Sul - que apresentou a intenção de qualificar o processo de planejamento estadual a partir da construção do planejamento regional e da identificação das diversidades existentes nas regiões de saúde. Este Estado, por mais que ainda não esteja realizando claramente um processo de planejamento regional em seu território, apresenta grandes avanços quanto ao processo de regionalização e descentralização de suas ações e serviços de saúde ao se analisar o plano estadual de saúde.

Quanto às diretrizes de uma agenda estratégica, estas podem ser entendidas como as intenções macro estratégicas de um plano, que dependerão de objetivos, ações e metas para que sejam alcançadas. A partir desta definição é possível entender que as diretrizes de um plano devem construir seus objetivos, ações e metas visando alcançar estes ideais.

As diretrizes que expressaram o planejamento regional apresentam conteúdo bastante variado e rico, como: fortalecimento da regulação, da descentralização, do planejamento regional, da gestão estratégica, da conformação das redes, do reconhecimento das necessidades da população, da melhoria da assistência, da implementação de um novo modelo de gestão (COAP), e até mesmo como garantia da política de investimentos em saúde. No entanto, observou-se que as diretrizes que mais se repetem entre os planos são as que buscam o fortalecimento do planejamento regional, da regulação e do modelo político de descentralização.

Quanto às ações e metas encontradas, observou-se que estas também foram bastante diversificadas. Essa característica pode estar associada à especificidade com que foram construídas as diretrizes dos planos. No entanto, foi possível identificar que há maior frequência entre as ações e metas que propõe 0 fortalecimento das CIR's e CIB's, a construção do PDR, do PDI, da PPI, do COAP e dos mapas da saúde. Este resultado torna-se positivo por se levar em conta que 0 fortalecimento das CIR's é um fator fundamental para a elaboração, monitoramento, avaliação e incentivo à realização do planejamento regional. A construção do PDR e PDI também são fundamentais para a consolidação das regiões, mas não podem por si só configurar a realização do planejamento regional. 
Apesar das diretrizes, objetivos, ações e metas terem apresentado características positivas para a evolução do processo de planejamento integrado e regionalizado nos Estados, a análise realizada em questão de como os Estados realizam este planejamento regional indica resultados não muito satisfatórios. Dos 5 planos estaduais que descreveram a forma como foram organizados os processos de planejamento regional, a sua maioria indica a formulação e construção do PDR e PDRI como a realização do planejamento regional.

Embora o processo de planejamento nestes Estados tenha descrito que foi construído a partir de oficinas regionais que contaram com a presença dos representantes das regionais, das CIR's, da Secretaria de Saúde, dos COSEMS, dos antigos CGR's, e dos conselhos de saúde, o resultado deste processo, na maioria dos planos descritos, foi o PDR ou PDRI.

Como já descrito durante os resultados e fundamentado no marco referencial deste estudo, o processo de planejamento integrado e regionalizado é constituído por 5 etapas, que vão da definição das regiões de saúde até a elaboração da PGASS e definição das responsabilidades orçamentárias e financeiras. De forma alguma, o processo de planejamento integrado e regionalizado deveria se resumir somente a elaboração dos PRI e PDRI (BRASIL, 2015).

Quanto aos responsáveis pela elaboração deste planejamento regional, observa-se que diversos atores estratégicos estiveram envolvidos no processo, porém, dos planos que informaram os atores responsáveis pelo planejamento regional todos informam as secretarias de saúde como responsáveis pela elaboração, monitoramento e avaliação, sendo o CONASS também citado em um plano. As CIR's não são apresentadas como os atores responsáveis pelo acompanhamento da elaboração dos planos, ou pelo monitoramento e avaliação, que seria o correto de acordo com o Manual de Planejamento do Ministério da Saúde (BRASIL, 2015b).

A última análise dos resultados deste estudo identificou como o planejamento estadual foi realizado. $O$ objetivo desta análise foi 0 de identificar a atuação das instâncias regionais na construção do plano estadual de saúde, assim como identificar a relevância que estas instâncias obtiveram no processo de planejamento. 
Como resultado desta análise, observou-se que outros cinco Estados - além daqueles que já mencionaram realizar planejamento regional e assinaram o COAP elaboraram seus planos estaduais a partir de metodologias que contaram com forte participação das instâncias regionais de saúde. Estes Estados foram o Mato Grosso do Sul, Acre, Maranhão, Pernambuco e São Paulo.

Nestes cinco Estados foram apresentadas metodologias de elaboração do planejamento estadual de saúde a partir da realização de oficinas ou seminários regionais, priorização das necessidades em saúde das regiões e forte participação das CIR's, dos Colegiados de Gestão Regional - CGR e das Diretorias Regionais de Saúde - DRS.

A metodologia de planejamento destes Estados chama atenção mesmo não tendo sido reconhecida como de planejamento regional ou integrado pelo próprio documento de planejamento. A aproximação com as regiões de saúde e sua realidade é fator positivo para o fortalecimento do processo de regionalização dos serviços de saúde e reconhecimento das regiões de saúde para a consolidação das redes regionais integrais de saúde.

Por fim, entende-se este resultado como um indício de fortalecimento da gestão regional. Entretanto, faz-se necessário maior governança entre as regiões de saúde para que haja consolidação das pactuações estabelecidas nas agendas estratégicas dos planos de saúde, levando em conta que as regiões não são entes federados dotados de autonomia financeira e de gestão plena, e o funcionamento das redes regionalizadas integrais de saúde geralmente dependem dos serviços ofertados pelas três esferas de gestão do SUS. Desta forma, a governança das regiões torna-se fator chave para a consolidação de todo o processo de planejamento regional e do plano (FLEURY et al, 2010). 


\section{CONSIDERAÇÕES FINAIS}

Com o desenvolvimento das políticas de descentralização e regionalização da saúde no Estado brasileiro, alguns mecanismos de qualificação deste processo surgiram em busca da efetivação da integralidade da oferta dos serviços de saúde pelo SUS. O planejamento integrado e regionalizado pode ser considerado como um destes mecanismos de qualificação do processo de regionalização da saúde em busca de maior governança regional.

Este estudo dedicou-se à descrição e análise do processo de planejamento regional no SUS, identificando onde e como ele foi realizado, e quais atores foram responsáveis por sua realização, segundo os planos estaduais de saúde. 0 planejamento integrado não foi escopo desta análise, devido a quase inexistência de sua citação durante o estudo dos planos de saúde, apesar de amplamente divulgado pela literatura. Nesta perspectiva, este estudo analisou os 26 planos estaduais de saúde, com exceção do Distrito Federal, em busca de compreender como se dá o processo de planejamento regional no país.

Em síntese, observou-se que o planejamento regional foi desenvolvido por poucos Estados brasileiros, e a maioria daqueles que o realizam, o consideraram apenas como a elaboração dos PDR's, PDl's e dos Mapas da Saúde. Observa-se ainda o descompromisso com o planejamento integrado e regionalizado, levando em conta a baixa quantidade de planos estaduais que citam estes processos em seus textos.

Entretanto, vale ressaltar que este estudo trata-se de uma análise documental, e todos os resultados foram levantados com base nas informações encontradas nos planos estaduais de saúde, o que representa uma limitação deste estudo. Neste caso, é possível que entre os Estados analisados, possa haver localidades em que o planejamento regional tenha sido realizado, mas não foi descrito no plano estadual de saúde.

A elaboração dos planos regionais é descrita como realizada de forma participativa a partir de oficinas ou encontros regionais contando com grande 
participação entre as Secretarias de Saúde, COSEMS, Conselhos de Saúde e instâncias colegiadas. No entanto, observou-se que o protagonismo deste processo é declarado como de responsabilidade das Secretarias Estaduais de Saúde, ficando as CIR's à margem deste processo, e atuando de forma tímida, tornando-se evidente a necessidade de fortalecimento destas instâncias, como indicado inclusive em diversas agendas estratégicas analisadas.

Quanto ao processo de regionalização descrito nos planos, e as diretrizes, objetivos e metas declaradas nas agendas, identificou-se uma deficiência grande no que diz respeito às estratégias para a consolidação das RRAS, uma vez que estas estão voltadas apenas para a oferta de serviços, ficando evidente que tais redes estão sendo construídas sem considerar as necessidades regionais a partir de indicadores também regionais. Sendo assim, a elaboração dos planos de saúde, utilizando indicadores regionais, torna-se fundamental para a elaboração de redes regionalizadas e integrais de saúde.

A Assinatura do COAP também foi identificada como um nó crítico no processo de construção do planejamento integrado e regionalizado, uma vez que o comprometimento com sua assinatura significa firmar compromissos com a gestão regional e solidária. Como resultado, a maioria das agendas estratégicas dos planos apontaram a intenção de firmar tal compromisso. Mesmo assim, observou-se a baixa adesão ao COAP, revelando pouco comprometimento dos Estados com suas agendas estratégicas.

Recomenda-se, portanto, a elaboração do processo de planejamento integrado e regionalizado para a garantia de maior alcance e resolubilidade das metas definidas pelas agendas estratégicas, uma vez que o planejamento em saúde deve ser um processo permanente que acompanhará as mudanças necessárias para atingir tais metas, devendo também, ser constantemente discutido e pactuado entre as regiões de saúde e as esferas de gestão do SUS.

Faz-se necessário ainda, outros estudos para analisar a governança exercida entre as regiões de saúde, uma vez que o nível de governança entre as regiões implicará diretamente na capacidade de execução e cumprimento das agendas estabelecidas, proporcionando maior efetividade na prestação de serviços de saúde e na consolidação das redes regionalizadas e integrais de saúde. 


\section{REFERÊNCIAS BIBLIOGRÁFICAS}

BARDIN, L. Análise de conteúdo (L. de A. Rego \& A. Pinheiro, Trads.). Lisboa: Edições 70, 2006.

BRASIL. Regionalização é o caminho. Reflexões, diálogos e narrativas sobre as Regiões de Saúde no Estado de São Paulo. Cadernos COSEMS/SP, São Paulo, v. 4, $1^{\circ}$ edição, 91 pg. 2015a.

BRASIL. Ministério da Saúde (MS). Manual de planejamento no SUS. Ministério da Saúde; Fundação Oswaldo Cruz. Brasília: Ministério da Saúde; 2015b.

BRASIL. Comissão Intergestores Tripartite. Resolução $n^{\circ} 1$, de 29 de setembro de 2011.

BRASIL. Conferência Nacional de Saúde, 5, Brasília, 1975. Anais... Brasília: Ministério da Saúde, 1975

BRASIL. Conferência Nacional de Saúde; 6, Brasília, 1977. Anais... Brasília: Ministério da Saúde, 1977

BRASIL. Conferência Nacional de Saúde; 7, Brasília, 1980. Anais... Brasília: Ministério da Saúde, 1980

BRASIL. Constituição da República Federativa do Brasil. Brasília: Senado Federal, Subsecretaria de Edições Técnicas, 1988.

BRASIL. Decreto 7.508 de 28 de junho de 2011: Regulamentação da Lei $n^{\circ}$ 8.080/90. Ministério da Saúde. Secretaria de Gestão Estratégica e Participativa. - 1. Ed., 5. Reimpr. Brasília: Ministério da Saúde, 2014.

BRASIL. Lei 8.080/89. Lei Orgânica da Saúde.

BRASIL. Ministério da Saúde (MS). Secretaria de Atenção à Saúde. Departamento de Regulação, Avaliação e Controle de Sistemas. Diretrizes para a programação pactuada e integrada da assistência à saúde. Brasília: Ministério da Saúde; 2006. 
BRASIL. Ministério da Saúde (MS). Sistema de Planejamento do SUS (Planeja SUS): Uma construção coletiva - trajetória e orientações dae operacionalização. Ministério da Saúde; Organização Pan-americana da Saúde. Brasília: Ministério da Saúde; 2009.

BRASIL. Principais marcos normativos da gestão interfederativa do SUS / Ministério da Saúde, Secretaria de Gestão Estratégica e Participativa, Departamento de Articulação Interfederativa. 1. Ed., 1. Reimp. - Brasília: Ministério da Saúde, 2014.

BRASIL. Resolução CIT n01, de 29 de setembro de 2011. Estabelece diretrizes gerais para a instituição de Regiões de Saúde no âmbito do Sistema Único de Saúde (SUS), nos termos do Decreto № 7.508, de 28 de junho de 2011.

CAMPOS, Gastão Wagner de Sousa. Regionalização em debate. A regionalização é parte do caminho para fortalecimento do SUS: para atravessar o círculo de giz in Regionalização é o caminho. Reflexões, diálogos e narrativas sobre as Regiões de Saúde no Estado de São Paulo. Cadernos COSEMS/SP, São Paulo, v. 4, $1^{\circ}$ edição, p 59 - 66. 2015.

CARDOSO, A. J. C. Curso de Planejamento Situacional em Saúde. Escola Nacional de Administração Pública. Diretoria de Formação Profissional. Coordenação-Geral de Projetos Especiais, Brasília, V. 1, p.21, Julho. 2013.

CHORNY, Adolfo H. Planificacion em salud: viejas ideas em nuevos ropajes. CUadernos Médicos Sociales, Rosário, v. 73, p 5-30, 1998.

FLEURY, Sonia; OUVERNEY, Assis Luiz Maffort; KRONEMBERGER, Thais Soares; ZANI, Felipe Barbosa. Governança local no sistema descentralizado de saúde no Brasil. Rev Panam Salud Publica. 2010;28(6):446-55.

GIL, Antônio Carlos; LICHT, René Henrique Gotz; YAMAUCHI, Nancy Itomi. Regionalização da Saúde e Consciência Regional. HYGEIA: Rev. Brasileira de Geografia Médica e da Saúde. 2(3): 35-46, 2006.

GIL, Célia Regina Rodrigues. Aspectos Evolutivos do Conceito de Regionalização em Saúde. Semina: Ci. Biol./Saúde, Londrina, v, 16, n. 2, p. 204 - 207, jun. 1995

LUZ, M.T. As Instituições Médicas no Brasil: instituições e estratégias de hegemonia . Rio de Janeiro: Graal, 1986. 
MATUS, Carlos. Política, Planificacion y Gobierno. Washington D.C. Septembre 1987.

MENDES, Eugênio Vilaça. O sistema unificado e descentralizado de saúde no atual contexto da reforma sanitária brasileira. In: SEMINÁRIO INTERISTITUCIONAL SOBRE A REFORMA SANITÁRIA E A ORGANIZAÇÃO DOS SERVIÇOS DE SAÚDE, 1987, Natal, (Mimeo)

OPAS, 1964. Informe Dawson sobre el futuro de los servicios medicos y afines 1920. Washington, D. C. Organizacion Panamericana de La Salud, 1964.

PAIM, Jairnilson Silva. O que é o SUS. Rio de Janeiro: Editora Fiocruz, 2009.

SANTOS, Lenir. Regionalização em debate. Sim, a regionalização é o caminho in Regionalização é o caminho. Reflexões, diálogos e narrativas sobre as Regiões de Saúde no Estado de São Paulo. Cadernos COSEMS/SP, São Paulo, v. 4, $1^{\circ}$ edição, p 54 - 59. 2015.

SANTOS, Lenir; CAMPOS, Gastão Wagner de Sousa. SUS Brasil: A região de Saúde como Caminho. Saúde e Sociedade, v.24, n.2, p.438-446, 2015.

TANCREDI, Francisco Bernardini; BARRIOS, Susana Rosa Lopez; FERREIRA, Jose Henrrique Germann; Saúde \& Cidadania. Planejamento em Saúde. Para Gestores Municipais de Saúde. Instituto para o desenvolvimento da saúde; Núcleo de Assistência Médico Hospitalar - NAMH/FSP - USP; Banco ITAU. São Paulo, 1998.

VIANA, Ana Luiza d'Ávila; LIMA, Luciana Dias. Regionalização e relações federativas na política de saúde do Brasil. Rio de Janeiro, v. 1, 206p, 2011. 


\section{ANEXOS}

\section{Anexo 01 - MATRIZ PARA ANÁLISE DOS PLANOS ESTADUAIS}

\begin{tabular}{|c|c|c|c|c|c|c|c|c|c|c|c|c|c|c|c|c|}
\hline \multicolumn{3}{|c|}{ EIXO DESCRITIVO } & \multicolumn{7}{|c|}{ EIXO REGIONALIZAÇÃO } & \multicolumn{5}{|c|}{ EIXO PLANEJAMENTO REGIONAL } & \multicolumn{2}{|c|}{ EIXO PLANEJAMENTO ESTADUAL } \\
\hline ESTADO & $\begin{array}{l}\text { População } \\
\text { (IBGE 2010) }\end{array}$ & $\begin{array}{l}\text { No de Regiōes de } \\
\text { Saúde no Estado }\end{array}$ & $\begin{array}{c}\text { OPlano Estadual } \\
\text { possui componente } \\
\text { regional (SIM/NÃO) }\end{array}$ & \begin{tabular}{|c|} 
Indicadores da análise de \\
situação foram construídos \\
na base Regional (R), \\
Municipal (M), Estadual (E) \\
(SIMNNÃO)
\end{tabular} & $\begin{array}{c}\text { Utiliza } \\
\text { PDR? } \\
\text { (SIMNÃ̃o) }\end{array}$ & \begin{tabular}{|c|} 
Oplanio \\
Estadual \\
prevê 0 \\
fortalecime \\
nto da \\
nD?
\end{tabular} & \begin{tabular}{|c|} 
O Plano \\
Estadual \\
prevế \\
assinatura \\
do COAP?
\end{tabular} & $\begin{array}{l}\text { Quais foram as } \\
\text { açōes/metas } \\
\text { previstas no } \\
\text { ambito da } \\
\text { regionalização? }\end{array}$ & $\begin{array}{l}\text { As metas foram } \\
\text { previstas para a } \\
\text { regiâo de saúde? } \\
\text { (SIM/NÃO) }\end{array}$ & $\begin{array}{c}\text { Plano Estadual } \\
\text { prevê PR? } \\
\text { (SIM/NÃO) }\end{array}$ & $\begin{array}{c}\text { Foram previstas } \\
\text { ações/metas no ambito } \\
\text { do planejamento } \\
\text { regional? (SIM/NÃO) }\end{array}$ & $\begin{array}{c}\text { Quais foram as } \\
\text { açōes previstas } \\
\text { no ambito do } \\
\text { PR? } \\
\text { (DESCREVER) }\end{array}$ & $\begin{array}{c}\text { Como o } \\
\text { planejamento } \\
\text { regional foi } \\
\text { realizado? }\end{array}$ & \begin{tabular}{|c|} 
Componente \\
regional do Plano \\
prevê \\
responsáveis \\
pelo PR?
\end{tabular} & $\begin{array}{c}\text { O Plano Estadual } \\
\text { Prevê fortalecimento } \\
\text { ou aprimoramento da } \\
\text { PPI? }\end{array}$ & $\begin{array}{l}\text { Como o plano } \\
\text { estadual foi } \\
\text { construido? }\end{array}$ \\
\hline \multicolumn{17}{|l|}{ Acre } \\
\hline \multicolumn{17}{|l|}{ Alagoas } \\
\hline \multicolumn{17}{|l|}{ Amapá } \\
\hline \multicolumn{17}{|l|}{ Amazonas } \\
\hline \multicolumn{17}{|l|}{ Bahia } \\
\hline \multicolumn{17}{|l|}{ Ceará } \\
\hline \multicolumn{17}{|l|}{ Espirito Santo } \\
\hline \multicolumn{17}{|l|}{ Goiás } \\
\hline \multicolumn{17}{|l|}{ Maranhão } \\
\hline \multicolumn{17}{|l|}{ Mato Grosso } \\
\hline \multicolumn{17}{|c|}{ Mato Grosso do Sul } \\
\hline \multicolumn{17}{|l|}{ Minas Gerais } \\
\hline \multicolumn{17}{|l|}{ Pará } \\
\hline \multicolumn{17}{|l|}{ Paraiba } \\
\hline \multicolumn{17}{|l|}{ Paraná } \\
\hline \multicolumn{17}{|l|}{ Pernambuco } \\
\hline \multicolumn{17}{|l|}{ Piauí } \\
\hline \multicolumn{17}{|l|}{ Rio de Janeiro } \\
\hline \multicolumn{17}{|c|}{ Rio Grande do Norte } \\
\hline \multicolumn{17}{|c|}{ Rio Grande do Sul } \\
\hline \multicolumn{17}{|l|}{ Rondonia } \\
\hline \multicolumn{17}{|l|}{ Roraima } \\
\hline \multicolumn{17}{|l|}{ Santa Catarina } \\
\hline São Paulo & & & & & & & & & & & & & & & & \\
\hline Sergipe & & & & & & & & & & & & & & & & \\
\hline Tocantins & & & & & & & & & & & & & & & & \\
\hline
\end{tabular}




\section{Anexo 02 - ARTIGO SUBMETIDO À REVISTA PHYSIS}

Physis Revista de Saúde Coletiva

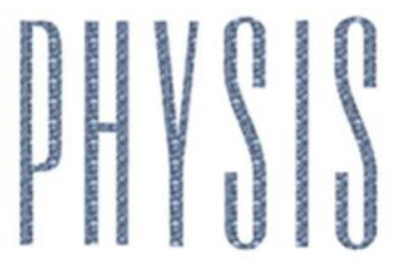

ESTUDO SOBRE O PLANEJAMENTO REGIONAL NOS ESTADOS BRASILEIROS

\begin{tabular}{r||l|}
\hline \hline Journal: & Physis Revista de Saúde Coletiva \\
\hline \hline Manuscript ID & PHYSIS-2016-0051 \\
\hline \hline Keyword: & $\begin{array}{l}\text { Planejamento Regional, Planejamento em Saúde, Regionalização, Gestão } \\
\text { em Saúde }\end{array}$ \\
\hline \hline
\end{tabular}

SCHOLARONE ${ }^{m}$

Manuscripts 


\section{ESTUDO SOBRE O PLANEJAMENTO REGIONAL NOS ESTADOS BRASILEIROS}

STUDY ABOUT REGIONAL PLANNING ON BRAZILIAN STATES

Título curto: ANÁLISE DO PLANEJAMENTO REGIONAL NO BRASIL

\section{ANALYSIS OF REGIONAL PLANNING IN BRAZIL}

\section{INTRODUÇÃO}

A descentralização do Sistema Único de Saúde (SUS), instituído na Constituição Federal de 1988, e definido anteriormente na criação do Sistema Único e Descentralizado de Saúde (SUDS), estimulou uma divisão dos poderes da administração pública na prestação dos serviços de saúde, com ênfase no processo de municipalização. Entretanto, percebeu-se que a descentralização voltada para a municipalização dos serviços poderia proporcionar um conjunto de sistemas de saúde municipais e estaduais fragmentados, isolados e independentes, que não teriam condições de sustentar seus serviços de saúde de maneira plena e de atender de maneira integral as necessidades de sua população (BRASIL, 2015a).

Desta forma, a descentralização da política de saúde articulou-se à regionalização quando ficou claro para os gestores a necessidade de articulação politicaadministrativa para superação de tal fragmentação. Ou seja, apesar de não ter sido movimento claro na consolidação da universalidade e da integralidade do sistema de saúde, a descentralização só poderia atingir tais objetivos se acompanhada de um processo claro de regionalização do sistema. 
Por definição, a regionalização do SUS trata-se de uma estratégia para a reorganização e orientação da descentralização das ações e serviços de saúde, proporcionando direcionalidade regional para as políticas de saúde, reorientando os processos de negociação e articulação interfederativa entre os gestores do SUS (GIL et al, 2006; BRASIL, 2006).

A regionalização no SUS teve avanço importante a partir do ano 2000, principalmente se considerarmos a evolução de seus marcos legais, com destaque para a edição da NOAS em 2002, do Pacto Pela Saúde em 2006 e do Decreto 7.508 em 2011. Dessa forma, durante a década de 1990 pouco se produziu sobre a regionalização no SUS, mas sim, como seriam desenvolvidos os processos de descentralização e municipalização do sistema de saúde.

No entanto, vale ressaltar que a Constituição Federal de 1988 e a Lei Orgânica da Saúde já previam que a organização e oferta dos serviços de saúde deveriam respeitar o princípio da regionalização. O Decreto 7.508 é um importante documento que veio para regulamentar a Lei 8.080, no que tange à organização do SUS quanto à regionalização, estabelecendo, por exemplo, o Contrato Organizativo de Ação Pública COAP, o conceito de região de saúde, a realização do planejamento integrado e regionalizado, a construção do Mapa da Saúde, e ainda, organizar a conformação da oferta das ações e serviços de saúde por meio das redes regionalizadas e integradas da saúde (BRASIL, 2011).

De acordo com o Decreto, a região de saúde é definida como:

“...o espaço geográfico contínuo constituído por agrupamentos de municípios limítrofes, delimitado a partir de identidades culturais, econômicas e sociais e de rede de comunicação e infraestrutura de transportes compartilhados, com a finalidade de integrar a organização, o planejamento e a execução de ações e serviços de saúde (art. $2^{\circ}$, I)". 
Ressalta-se que nesta região o usuário deve encontrar os serviços adequados que sejam capazes de atender as suas necessidades de saúde. Sendo assim, neste espaço definido como região de saúde devem ser oferecidos, no mínimo, os serviços de: 1) atenção primária; 2) urgência e emergência; 3) atenção psicossocial; 4) atenção ambulatorial especializada e hospitalar; 5) vigilância em saúde. A oferta destes serviços será por meio da rede integrada e regionalizada, que deverá ser pactuada entre os entes federativos que integrarem a região (BRASIL, 2011).

O Decreto trouxe ainda o planejamento regional, ao dispor em seu artigo $6^{\circ}$ que a região será referência para a transferência de recursos entre os entes federados. Esse movimento faz com que a região de saúde e suas características, como população e situação sociossanitária, sejam avaliadas para definir a necessidade populacional, não mais a partir de cada ente federado, mas a partir de um território delimitado, proporcionando maior possibilidade de enfrentar as iniquidades territoriais.

Em síntese, a realização do Planejamento Regional Integrado consiste na elaboração do planejamento por cada ente federado, considerando suas especificidades sociais, econômicas, políticas e sanitárias para além do seu próprio território, levando em conta assim, a necessidade da população da sua região de saúde, e não apenas do seu território administrativo (BRASIL, 2015b).

O planejamento é um importante instrumento para promover a governança das regiões de saúde e deve ser o indutor de políticas para a região, devendo ser realizado de modo regionalizado e integrado, de maneira a promover maior integralidade na oferta de serviços no SUS e governança das regiões.

Portanto, o planejamento estadual de saúde deve ser construído de maneira integrada e ascendente entre os municípios e regiões de saúde, levando em conta que o 
planejamento é parte do arcabouço legal do SUS, e de acordo com lei 8.080, os planos de saúde serão requisitos necessários para o repasse de recursos, de controle e auditoria (BRASIL, 2009).

Sendo assim as estratégias para consolidação da regionalização em saúde, como o fortalecimento ou construção das ferramentas de planejamento regional como a Programação Pactuada e Integrada (PPI), o Plano Diretor de Regionalização (PDR), o Plano Diretor de Investimentos (PDI), e as Comissões Intergestores Regionais (CIR), deverão ser estabelecidas pelos planos de saúde, demonstrando a intenção de qualificar este processo. Além destes requisitos, o plano de saúde expressa ainda a metodologia na qual o processo de planejamento foi desenvolvido, se ascendente, regionalizado ou não.

Observando as considerações anteriores, o objetivo deste estudo foi identificar se o planejamento regional (PR) foi abordado pelos planos estaduais de saúde dos Estados brasileiros, a partir da análise dos 26 planos estaduais de saúde construídos, com exceção do Distrito Federal, nos anos de 2012 a 2015. Além disso, buscou-se descrever a existência de estratégias e metas para a operacionalização do PR e a indicação de atores responsáveis pela sua execução.

\section{METODOLOGIA}

Trata-se de um estudo qualiquantitativo, descritivo, de amplitude nacional. Consistiu numa análise documental dos 26 planos estaduais de saúde dos estados brasileiros com vigência entre os anos de 2012 a 2015. Na coleta dos dados o plano de saúde do Distrito Federal (DF) foi excluído, pois não há conformação de municípios em seu território. Esse critério foi considerado visto à definiçãa de região de saúde adotada pelo Ministério da Saúde, sendo o DF considerado uma região de saúde em sua totalidade. 
Os planos estaduais de saúde foram coletados a partir da busca em repositórios públicos dos portais das Secretarias Estaduais de Saúde ou fornecidos pelo Departamento de Articulação Interfederativa da Secretaria de Gestão Estratégica e Participativa do Ministério da Saúde (DAI/SGEP/MS), após solicitação formal pelo pesquisador.

Para a análise dos planos foi empregada a técnica de análise de conteúdo (BARDIN, 2006), com categorias estabelecidas a priori. Foi elaborada uma matriz de análise e categorização dos dados, que serviu de roteiro para garantir maior orientação e direcionalidade ao pesquisador. Foram construídos 17 descritores de análise que formaram, em conjunto, 4 categorias ou eixos de análise: I) EIXO DESCRITIVO; II) EIXO REGIONALIZAÇÃO; III) EIXO PLANEJAMENTO REGIONAL; IV) EIXO PLANEJAMENTO ESTADUAL, que serão explorados na seção de resultados do presente artigo.

Abaixo estão descritos os eixos e seus subeixos, de acordo com os achados dos planos estaduais de saúde:

I) EIXO DESCRITIVO;

a) Estado

b) População

c) Número de regiões de saúde do estado

II) EIXO REGIONALIZAÇÃO;

d) Previsão de metas para a região

e) Fortalecimento da CIR

f) Assinatura do COAP

g) Utilização do PDR

h) Presença de componente regional no plano

i) Indicadores da análise de situação em base municipal, regional ou estadual 
j) Previsão para a regionalização

III) EIXO PLANEJAMENTO REGIONAL;

k) Previsão para Planejamento Regional

1) Previsão de ações, metas, diretrizes ou objetivos no âmbito do Planejamento Regional

m) O que foi previsto no âmbito do planejamento regional

n) Responsáveis pelo Planejamento Regional

o) Realização e construção do planejamento regional

IV) EIXO PLANEJAMENTO ESTADUAL;

p) Previsão de fortalecimento da PPI

q) Construção do Plano Estadual

Este estudo dispensou aprovação do Comitê Nacional de Ética em Pesquisa (CONEP) por se tratar de análise documental de arquivos públicos.

\section{RESULTADOS E DISCUSSÃO}

A análise dos planos possibilitou a identificação de aspectos relevantes ao estudo do processo de planejamento integrado e regionalizado no país, desenvolvidos em três categorias de análise, denominadas eixos e que conformarão a descrição e discussão dos resultados do presente artigo.

A primeira categoria dizia respeito ao Eixo Descritivo, o que significou descrever as características de cada Estado, como sua população e quantidade de regiões de saúde, conforme apresentado na Tabela 1.

\section{INSERIR TABELA 1}

Nesta categoria levou-se em conta a quantidade de planos de saúde que apresentaram em seu texto as palavras planejamento regional ou planejamento integrado. Em apenas 16 planos de saúde foram encontradas estas palavras, o que significa que em ao menos 10 planos estaduais a discussão sobre o planejamento integrado nem ao menos foi levantada. Este resultado pode estar associado à 
desqualificação da agenda estratégica do Estado e seu plano de saúde, indicando um descompromisso com as políticas e estratégias de planejamento integrado e até mesmo ao processo de regionalização nos Estados, no momento de produção do plano estadual de saúde.

Os estados que mencionaram, demonstraram intenção, apoio ou realização do planejamento integrado e regionalizado foram: Acre, Alagoas, Amazonas, Bahia, Ceará, Maranhão, Mato Grosso do Sul, Minas Gerais, Pará, Pernambuco, Rio de Janeiro, Rio Grande do Norte, Rio Grande do Sul, Roraima, Sergipe e Tocantins.

Vale ressaltar, neste contexto, a importância do Plano de Saúde, que foi regulamentado pelo artigo 36 da Lei Nº 8.080 de 1990 - dita Lei Orgânica da Saúde como instrumento básico de planejamento setorial, cabendo aos Conselhos de Saúde formular diretrizes para sua elaboração e aprovação, a fim de que os recursos da esfera federal destinados as ações e serviços de saúde sejam repassados aos estados (BRASIL, 1990). Ainda de acordo com a Lei Orgânica da Saúde, em seu $\S 2^{\circ}$, determina-se que será vedada a transferência de recursos para o financiamento de ações não previstas nos planos de saúde. Esta determinação fundamenta ainda mais a relevância dos planos de saúde como instrumento de governo, cabendo aos gestores construir com sabedoria seus planos (BRASIL, 1990).

Outro quesito analisado neste eixo foi referente à possível correlação do número populacional e de regiões de saúde com a realização ou não do planejamento regional. Observou-se que a maioria dos Estados de maior população mencionaram o planejamento regional, sendo eles os estados de São Paulo como o de maior população, com 41.262.199 de habitantes, Minas Gerais com 19.597.330 de habitantes, Rio de Janeiro com 16.112.637 de habitantes, e o Estado da Bahia com 14.021.432 de 
habitantes. Ressalta-se que o estado de São Paulo, não mencionou a realização do planejamento regional em seu plano de saúde, porém apresentou grande participação das regiões de saúde e das instâncias regionais na elaboração do seu plano estadual.

Os Estados com a maior quantidade de regiões de saúde são Minas Gerais (77), São Paulo (63), Rio Grande do Sul (30) e Bahia (28). Entre estes quatro Estados, apenas São Paulo não mencionou em seu texto base o planejamento integrado e regionalizado apesar de ter realizado o planejamento estadual contando com grande participação das instâncias regionais. Quanto aos Estados com a menor quantidade de regiões de saúde, observou-se que a menção ao planejamento regionalizado em seu texto não está constante.

O segundo eixo de análise - Eixo Regionalização - identificou aspectos referentes ao processo de regionalização nos Estados, e sua síntese foi descrita no Quadro 1. Esta análise tornou-se tão importante quanto o estudo do planejamento regional propriamente dito, uma vez que a consolidação das políticas de descentralização e regionalização da saúde nos Estados brasileiros devem ser ordenadoras do processo de planejamento integrado. Afinal, como seria possível analisar um processo de planejamento integrado entre entes federados e regiões de saúde sem identificar as devidas conformações regionais estabelecidas pelos Estados?

\section{INSERIR QUADRO 1}

Os resultados iniciais do segundo eixo apontaram que praticamente todos os Estados apresentaram metas para a região de saúde, sendo que em 24 planos estaduais as metas na agenda estratégica foram previstas para a região, os outros 2 planos estaduais ou não informaram ou não apresentaram metas para a região de saúde. 
Dentre os 24 planos estaduais informados acima, seis deles apresentaram até cinco metas regionais em toda a agenda estratégica, um apresentou metas regionais apenas para os objetivos que envolvem o tema da regionalização, e em outro foram abordadas metas regionais apenas para a construção e instalação de redes temáticas. Os demais planos estaduais apresentaram outras metas para a região.

Esse resultado se contrapõe ao encontrado na categoria que identifica em quais bases os indicadores da análise de situação estão dispostos, se estaduais, regionais ou municipais, conforme ilustrado na TABELA 2. Observou-se que, mesmo tendo muitos planos que não organizaram suas análises de situação considerando as bases regionais, praticamente todos os planos propõem metas para as regiões de saúde na agenda estratégica.

\section{INSERIR TABELA 2}

Outra observação importante está na alta frequência com que aparecem metas regionais voltadas para a construção das redes regionalizadas de atenção à saúde (RRAS). A maioria dos planos apresenta metas regionais voltadas para construção ou implementação das redes temáticas ou das RRAS. Em sua maioria, as metas regionais estão voltadas para a consolidação da oferta de serviços nas regiões de saúde, no entanto, as análises de situação na maioria dos planos não se atem em construir indicadores regionais para identificar as condições de saúde da população da região. Então, como fortalecer o processo de regionalização nos Estados se a região está voltada apenas para o provimento da oferta de serviços?

Esta observação nos leva a identificar que os Estados brasileiros estão buscando, mesmo que de maneira ainda inconsistente, organizar a oferta de seus serviços de saúde a partir de redes regionalizadas. No entanto, a demanda ou oferta de serviços de saúde 
não está sendo dimensionada a partir das necessidades regionais. Esta é uma observação apontada, inclusive, por diversos planos de saúde que também reconheceram os serviços de saúde sendo planejados a partir da oferta, e não da demanda e real necessidade da população.

Quanto ao fortalecimento das CIR's, dentre os 26 planos analisados, 15 apresentaram diretrizes, objetivos ou metas que previam o seu fortalecimento, oito não apresentaram a intenção de fortalecer as CIR, e três não informaram devido inexistência de diretrizes objetivos ou metas na agenda estratégica. Observa-se que as ações, metas ou diretrizes previstas com este objetivo estão voltadas com maior frequência para o reconhecimento, ampliação, fortalecimento e qualificação das CIR's. Estas considerações apontam para o reconhecimento de uma estrutura ainda em desenvolvimento, que está em formação ou consolidação.

Em síntese, observou-se que a construção e fortalecimento das CIR’s ainda não é unanimidade nos planos de saúde. Entretanto, apesar das CIR’s terem sido estabelecidas pelo Decreto 7.508 (BRASIL, 2011), todos os planos analisados neste estudo foram desenvolvidos entre os anos de 2011 e 2012. Significa que no momento em que estes planos estavam em construção, o marco normativo que institui as CIR's estava sendo implementado, e neste contexto, entende-se que os planos de saúde, em sua totalidade, deveriam prever em suas agendas a construção, ampliação, ou, no mínimo, a implementação das CIR's nas regiões.

A mesma análise se faz quanto à assinatura do COAP, em que se encontrou na maioria dos planos de saúde a intenção de assina-lo (17 planos), implementa-lo (26 planos) ou de proporcionar sua adesão (26 planos). No entanto, o que se observa em 2016 - após o termino da vigência dos planos analisados 2012 a 2015 - é que mesmo 
tendo sido objetivo firmado nos planos de saúde estaduais, a assinatura do COAP só se consolidou em dois Estados brasileiros: Mato Grosso do Sul e Ceará.

Assim como as CIR’s, o COAP foi estabelecido em 2011 pelo decreto 7.508, o que significa que também esteve em alta a sua discussão durante a elaboração dos planos estaduais de saúde. Por outro lado, mesmo sendo sua assinatura bastante pleiteada pelos planos estaduais de saúde, o COAP obteve baixíssima adesão até o ano de 2016.

A baixa adesão ao COAP pelos entes federados pode ser explicada por diversos fatores e dificuldades já levantados em outros estudos. Uma das importantes dificuldades que podemos apontar, é o receio que os gestores possuem em se comprometer formalmente, por meio de contrato, com a gestão solidária entre si e os municípios vizinhos que compõe sua região de saúde (SANTOS e CAMPOS, 2015). Pode-se ainda apontar como razão para a dificuldade da regionalização a característica paternalista, patrimonialista e clientelista do poder no estado brasileiro, exercido pelos gestores nas três esferas de gestão (SANTOS e CAMPOS, 2015).

Além das dificuldades para a adesão ao COAP, outro fator que chama atenção nesta análise é o alto número de Estados que apresentam em seus planos o objetivo de assinar o COAP, e que ao final da vigência dos planos, não o fizeram. Nesta perspectiva, levanta-se ainda o questionamento da seriedade com que os gestores encaram os compromissos firmados nos planos de saúde. Seriam os planos de saúde apenas meras peças formais estipuladas por lei, mas que seus objetivos não são buscados de forma seria pelos gestores? Ou o contexto não favoreceu?

No que se refere a utilização do PDR, foram identificados 18 planos estaduais de saúde que o utilizaram na conformação de suas regiões e oito planos estaduais não 
apresentaram informações quanto ao PDR em todo o seu texto base ou em sua agenda estratégica.

Em uma de suas três advertências, Carlos Matus afirma que "devemos entender a planificação como uma dinâmica de cálculo que precede e preside a ação, que não cessa nunca, sendo processo contínuo, que acompanha a realidade mutável” (MATUS, 1987). Neste caso, o processo de planejamento não pode ser encarado apenas como o plano, ou o documento fruto deste processo, tendo em vista que os cenários e realidades que configuram o mundo real sofrem alterações (CARDOSO, 2013).

Portanto, o documento plano torna-se apenas uma peça de vida efêmera, sendo assim o processo de planejamento em si, uma cultura que deve ser constante e permanente. Por sua vez, o plano, tal como o de saúde, também possui sua importância, devendo existir para que sejam documentados e firmados os acordos estabelecidos. Sendo assim, o plano deve apresentar os caminhos para onde se deseja seguir, é a expressão dos caminhos a serem seguidos para alcançar a visão de futuro (CARDOSO, 2013).

Para que o processo de planejamento seja constante e vivo, é preciso que haja monitoramento e avaliação constante das metas, sendo permanentemente revisado para se manter atual. Este resultado pode ser configurado como uma evidência da necessidade de realização do planejamento integrado e regionalizado. Uma vez que os planos foram elaborados e revisados permanentemente entre municípios, regiões e os Estados será possível construir agendas com maior comprometimento entre sua realização (TANCREDI et al, 1998).

A terceira análise realizada neste estudo identificou os aspectos e conformações do processo de planejamento integrado e regionalizado desenvolvido pelos Estados, 
denominado eixo III - Planejamento Regional. Neste momento, pode-se identificar quais Estados brasileiros realizaram o planejamento integrado e regionalizado, a relevância que o processo de planejamento integrado possuiu nos planos estaduais de saúde, e até mesmo o que alguns Estados entenderam por planejamento regional.

A princípio, observou-se que em 16 planos estaduais de saúde foram encontradas alguma das palavras chave para a identificação do planejamento regional. No entanto, em apenas 12 destes planos foram identificadas diretrizes, objetivos, ações ou metas que se referiram ao planejamento regional, apontando melhorias ou encaminhamentos com esta temática.

Foi possível ainda, observar que houve controvérsias quanto à definição do planejamento regional e sua nomenclatura já que os planos analisados adotaram diferentes palavras para se referir ao planejamento regional, como "Planejamento Participativo e Regionalizado", "Planejamento Regional da Atenção Básica", "Planejamento Integrado da Saúde” e o propriamente dito "Planejamento Regional".

Durante a análise, foi identificado apenas um descritor - demonstrado pelo estado do Rio Grande do Sul - que apresentou a intenção de qualificar o processo de planejamento estadual a partir da construção do planejamento regional e da identificação das diversidades existentes nas regiões de saúde. Este Estado, por mais que ainda não declarado em seu plano claramente um processo de planejamento regional, apresentou grandes avanços quanto ao processo de regionalização e descentralização de suas ações e serviços de saúde.

Quanto às diretrizes de uma agenda estratégica, estas puderam ser entendidas como as intenções macro estratégicas de um plano, que dependerão de objetivos, ações e metas para que sejam alcançadas (CARDOSO, 2013). A partir desta definição é 
possível entender que as diretrizes de um plano devem construir seus objetivos, ações e metas visando alcançar estes ideais.

Nos planos de saúde, as diretrizes que expressaram o planejamento regional apresentaram conteúdo bastante variado e rico, como: Fortalecimento da Regulação, da Descentralização, do planejamento regional, da gestão estratégica, da conformação das redes, do Reconhecimento das necessidades da população, da Melhoria da assistência, da Implementação de um novo modelo de gestão (COAP), e até mesmo como Garantia da política de investimentos em saúde. No entanto, observou-se que as diretrizes que mais se repetiram nos planos são as que buscaram o fortalecimento do Planejamento Regional, da regulação e do modelo político de descentralização.

Quanto às ações e metas encontradas, observou-se que estas também foram bastante diversificadas. Essa característica pode estar associada à especificidade com que foram construídas as diretrizes dos planos. No entanto, foi possível identificar que as metas mais frequentes foram: o fortalecimento das CIR's e CIB's; as ações de construção do PDR, da PPI, do PDI e do COAP, além da elaboracão dos mapas da saúde. Este resultado torna-se positivo por se levar em conta que o fortalecimento das CIR's é um fator fundamental para a elaboração, monitoramento, avaliação e incentivo a realização do planejamento regional. A construção do PDR e PDI também são fundamentais para a consolidação das regiões, mas não podem por si só configurar a realização do planejamento regional.

Apesar das diretrizes, objetivos, ações e metas terem apresentado características positivas para a evolução do processo de planejamento regionalizado nos Estados, a análise do planejamento regional indicou resultados não muito satisfatórios. Dos cinco planos estaduais que descreveram a forma como foram organizados os processos de 
planejamento regional, a sua maioria indicou apenas a formulação e construção do PDR e PDI como ferramenta para a consolidação do planejamento regional.

Conforme constou nos planos de saúde, embora o processo de planejamento nestes Estados tenha descrito que foi construído a partir de oficinas regionais que contaram com a presença dos representantes das regionais, das CIR's, da Secretaria de Saúde, dos COSEMS, dos antigos CGR's, e dos conselhos de saúde, o resultado deste processo, na maioria dos planos descritos, foi o PDR ou PDI.

O processo de planejamento integrado e regionalizado é constituído por cinco etapas, que incluem a definição das regiões de saúde, a análise de situação e elaboração do mapa da saúde, a elaboração da Programação Geral das Ações e Serviços de Saúde (PGASS) e a definição das responsabilidades orçamentárias e financeiras. De forma alguma, o processo de planejamento integrado e regionalizado deveria se resumir somente a elaboração dos PRI e PDI (BRASIL, 2015b).

Quanto aos responsáveis pela elaboração deste planejamento regional, observouse que diversos atores estratégicos estiveram envolvidos no processo, porém, dos planos que informaram os atores responsáveis pelo planejamento regional todos informam as secretarias de saúde como responsáveis pela elaboração, monitoramento e avaliação, sendo o CONASS também citado em um plano. As CIR’s não são apresentadas como os atores responsáveis pelo acompanhamento da elaboração dos planos, ou pelo monitoramento e avaliação, que seria o correto de acordo com o Manual de Planejamento do Ministério da Saúde (BRASIL, 2015b).

A última análise dos resultados deste estudo identificou como o planejamento estadual foi realizado, eixo IV - Planejamento Estadual. O objetivo desta análise foi o de identificar a atuação das instâncias regionais na construção do plano estadual de 
saúde, assim como identificar a relevância que estas instâncias obtiveram no processo de planejamento.

Como resultado desta análise, observou-se que outros cinco estados - além daqueles que já mencionaram realizar planejamento regional e assinaram o COAP elaboraram seus planos estaduais a partir de metodologias que contaram com forte participação das instâncias regionais de saúde. Estes Estados foram o Mato Grosso do Sul, Acre, Maranhão, Pernambuco e São Paulo.

Nestes cinco Estados foram apresentadas metodologias de elaboração do planejamento estadual de saúde a partir da realização de oficinas ou seminários regionais, priorização das necessidades em saúde das regiões e forte participação das CIR's, dos Colegiados de Gestão Regional - CGR e das Diretorias Regionais de Saúde DRS.

A metodologia de planejamento destes Estados chama atenção mesmo não tendo sido reconhecida como de planejamento regional ou integrado pelo próprio documento de planejamento. A aproximação com as regiões de saúde e sua realidade é fator positivo para o fortalecimento do processo de regionalização dos serviços de saúde e reconhecimento das regiões de saúde para a consolidação das redes regionais integrais de saúde.

Por fim, entende-se este resultado como um indício de fortalecimento da gestão regional. Entretanto, faz-se necessário maior governança entre as regiões de saúde para que haja consolidação das pactuações estabelecidas nas agendas estratégicas dos planos de saúde, levando em conta que as regiões não são entes federados dotados de autonomia financeira e de gestão plena, e o funcionamento das redes regionalizadas integrais de saúde geralmente dependem dos serviços ofertados pelas três esferas de 
gestão do SUS. Desta forma, a governança das regiões torna-se fator chave para a consolidação de todo o processo de planejamento regional e do plano (FLEURY et al, 2010).

\section{CONSIDERAÇÕES FINAIS}

Com o desenvolvimento das políticas de descentralização e regionalização da saúde no Estado brasileiro, alguns mecanismos de qualificação deste processo surgiram em busca da efetivação da integralidade da oferta dos serviços de saúde pelo SUS. O planejamento integrado e regionalizado pode ser considerado como um destes mecanismos de qualificação do processo de regionalização da saúde em busca de maior governança regional.

Este estudo dedicou-se à descrição e análise do processo de planejamento regional no SUS, identificando onde e como ele foi realizado, e quais atores foram responsáveis por sua realização, segundo os planos estaduais de saúde. O planejamento integrado não foi escopo dessa análise, devido à quase inexistência de sua citação durante o estudo dos planos de saúde, apesar de amplamente divulgado pela literatura. Nesta perspectiva, este estudo analisou os 26 planos estaduais de saúde, com exceção do Distrito Federal, em busca de compreender como ocorreu o processo de planejamento regional no país.

Em síntese, observou-se que o planejamento regional foi desenvolvido por poucos Estados brasileiros, e a maioria daqueles que o realizaram, o consideraram apenas como a elaboração dos PDRs, PDIs e dos Mapas da Saúde. Observou-se ainda o descompromisso com o planejamento integrado e regionalizado, levando em conta a baixa quantidade de planos estaduais que citam estes processos em seus textos. 
Entretanto, vale ressaltar que este estudo tratou-se de uma análise documental, e todos os resultados foram levantados com base nas informações encontradas nos planos estaduais de saúde, o que representa uma limitação deste estudo. Neste caso, é possível que entre os Estados analisados, possa haver localidades em que o planejamento regional tenha sido realizado, mas não foi descrito no plano estadual de saúde.

A elaboração dos planos regionais é descrita como realizada de forma participativa a partir de oficinas ou encontros regionais contando com grande participação entre as Secretarias de Saúde, COSEMS, Conselhos de Saúde e instâncias colegiadas. No entanto, observou-se que o protagonismo deste processo é declarado como de responsabilidade das Secretarias Estaduais de Saúde, ficando as CIR's à margem deste processo, e atuando de forma tímida, tornando-se evidente a necessidade de fortalecimento destas instâncias, como indicado inclusive em diversas agendas estratégicas analisadas.

Quanto ao processo de regionalização descrito nos planos, e as diretrizes, objetivos e metas declaradas nas agendas, identificou-se uma deficiência grande no que diz respeito às estratégias para a consolidação das RRAS, uma vez que estas estão voltadas apenas para a oferta de serviços, ficando evidente que tais redes estão sendo construídas sem considerar as necessidades regionais a partir de indicadores também regionais. Sendo assim, a elaboração dos planos de saúde, utilizando indicadores regionais torna-se fundamental para a elaboração de redes regionalizadas e integrais de saúde.

A Assinatura do COAP também foi identificada como um nó crítico no processo de construção do planejamento integrado e regionalizado, uma vez que o comprometimento com sua assinatura significa firmar compromissos com a gestão regional e solidária. Como resultado, a maioria das agendas estratégicas dos planos 
apontaram a intenção de firmar tal compromisso. Mesmo assim, observou-se a baixa adesão ao COAP, revelando pouco comprometimento dos Estados com suas agendas estratégicas.

Recomenda-se, portanto, a elaboração do processo de planejamento integrado e regionalizado para a garantia de maior alcance e resolubilidade das metas definidas pelas agendas estratégicas, uma vez que o planejamento em saúde deve ser um processo permanente que acompanhará as mudanças necessárias para atingir tais metas, devendo também, ser constantemente discutido e pactuado entre as regiões de saúde e as esferas de gestão do SUS.

Faz-se necessário ainda, outros estudos para analisar a governança exercida entre as regiões de saúde, uma vez que o nível de governança entre as regiões implicará diretamente na capacidade de execução e cumprimento das agendas estabelecidas, proporcionando maior efetividade na prestação de serviços de saúde e na consolidação das redes regionalizadas e integrais de saúde.

\section{AGRADECIMENTOS}

Este artigo é integrante do Estudo Análise do Processo de Regionalização em Saúde no Brasil, financiado pelo Conselho Nacional de Desenvolvimento Científico e Tecnológico ( $\mathrm{CNPq})$, e é fruto da dissertação de mestrado em Saúde Coletiva do primeiro autor.

\section{REFERÊNCIAS}

BARDIN, L. Análise de conteúdo (L. de A. Rego \& A. Pinheiro, Trads.). Lisboa: Edições 70, 2006. 
BRASIL. Decreto 7.508/2011. Regulamenta a Lei Orgânica da Saúde. Disponivel em: http://www.planalto.gov.br/ccivil_03/_ato2011-2014/2011/decreto/D7508.htm

BRASIL. Lei 8.080/90. Lei Orgânica da Saúde. Disponível em: http://www.planalto.gov.br/ccivil_03/leis/L8080.htm

BRASIL. Ministério da Saúde (MS). Manual de planejamento no SUS. Ministério da Saúde; Fundação Oswaldo Cruz. Brasília: Ministério da Saúde; 2015a.

BRASIL. Ministério da Saúde (MS). Sistema de Planejamento do SUS (Planeja SUS): Uma construção coletiva - trajetória e orientações dae operacionalização. Ministério da Saúde; Organização Pan-americana da Saúde. Brasília: Ministério da Saúde; 2009.

BRASIL. Ministério da Saúde (MS). Secretaria de atenção à saúde. Departamento de Regulação, Avaliação e Controle de Sistemas. Diretrizes para a programação pactuada e integrada da assistência à saúde. Brasília: Ministério da Saúde; 2006.

BRASIL. Regionalização é o caminho. Reflexões, diálogos e narrativas sobre as Regiões de Saúde no Estado de São Paulo. Cadernos COSEMS/SP, São Paulo, v. 4, $1^{\circ}$ edição, 91 pg. 2015 b.

CARDOSO, A. J. C. Curso de Planejamento Situacional em Saúde. Escola Nacional de Administração Pública. Diretoria de Formação Profissional. Coordenação-Geral de Projetos Especiais, Brasília, v. 1, p.21, 2013.

FLEURY, S.; OUVERNEY, A.L.M.; KRONEMBERGER, T.S; ZANI, F.B. Governança local no sistema descentralizado de saúde no Brasil. Rev Panam Salud Publica. v. 28. n. 6, p. 446-55, 2010. 
GIL, A.C; LICHT, R.H.G; YAMAUCHI, N.I. Regionalização da Saúde e Consciência Regional. HYGEIA: Rev. Brasileira de Geografia Médica e da Saúde, v.2. n. 3, p. 3546, 2006.

MATUS, Carlos. Política, Planificacion y Gobierno. Washington D.C. Septembre 1987. SANTOS, L.; CAMPOS, G.W.S. SUS Brasil: A região de Saúde como Caminho. Saúde e Sociedade, v.24, n.2, p.438-446, 2015.

TANCREDI, F.B.; BARRIOS, S.R.L.; FERREIRA, J.H.G. Planejamento em Saúde. Para Gestores Municipais de Saúde. In: Saúde \& Cidadania. Instituto para o desenvolvimento da saúde; Núcleo de Assistência Médico Hospitalar - NAMH/FSP USP; Banco ITAU. São Paulo, 1998. 


\section{ABSTRACT}

The regional health planning (RP) can be understood as an important strategy for strengthening the ascendant planning at the SUS, especially since the publication of Decree 7508 in 2011. From this premise, the objective of this study was to describe the RP was covered by state health plans of Brazilian states, for the 2012-2015 quadrennium, considering its prevalence; existence of strategies and goals for its operations and the statement of actors responsible for its implementation. This was a descriptive study, conducted through documental analisis of 26 state health plans available in the period, with the exception of the Federal District. Sixteen states cited the PR in their plans, however, only five declared build it. Twelve states cited strategies to operationalize the RP, in its more related to the director plan of regionalization, the construction of integrated agreed schedule, chief investment plan, the organizational contract of public action and health maps. The actors cited for this process were the State Health Departments and CONASS. The study identified that focused on regionalization initiatives have been described, however, are still timid progress achieved in the construction of regionalized planning and integrated health.

KEYWORDS: Regional Health Planning, Health Management, Health Planning. 